\title{
A new voxel-based model for the determination of atmospheric weighted mean temperature in GPS atmospheric sounding
}

\author{
Changyong $\mathrm{He}^{1,2}$, Suqin $\mathrm{Wu}^{2}$, Xiaoming Wang ${ }^{2}$, Andong $\mathrm{Hu}^{2}$, Qianxin Wang ${ }^{1}$, and Kefei Zhang ${ }^{1,2}$ \\ ${ }^{1}$ School of Environment and Spatial Informatics, China University of Mining and Technology, Xuzhou 221116, P.R. China \\ ${ }^{2}$ Satellite Positioning for Atmosphere, Climate and Environment (SPACE) Research Centre, School of Science, \\ Mathematical and Geospatial Sciences, RMIT University, Melbourne, VIC 3001, Australia \\ Correspondence to: Kefei Zhang (kefei.zhang@rmit.edu.au,profkzhang@cumt.edu.cn)
}

Received: 8 October 2016 - Discussion started: 1 December 2016

Revised: 16 March 2017 - Accepted: 5 April 2017 - Published: 7 June 2017

\begin{abstract}
The Global Positioning System (GPS) is a powerful atmospheric observing system for determining precipitable water vapour (PWV). In the detection of PWV using GPS, the atmospheric weighted mean temperature $\left(T_{\mathrm{m}}\right)$ is a crucial parameter for the conversion of zenith tropospheric delay (ZTD) to PWV since the quality of PWV is affected by the accuracy of $T_{\mathrm{m}}$. In this study, an improved voxel-based $T_{\mathrm{m}}$ model, named GWMT-D, was developed using global reanalysis data over a 4-year period from 2010 to 2013 provided by the United States National Centers for Environmental Prediction (NCEP). The performance of GWMT-D was assessed against three existing empirical $T_{\mathrm{m}}$ models - GTmIII, GWMT-IV, and GTm_N - using different data sources in 2014 - the NCEP reanalysis data, surface $T_{\mathrm{m}}$ data provided by Global Geodetic Observing System and radiosonde measurements. The results show that the new GWMT-D model outperforms all the other three models with a root-meansquare error of less than $5.0 \mathrm{~K}$ at different altitudes over the globe. The new GWMT-D model can provide a practical alternative $T_{\mathrm{m}}$ determination method in real-time GPS-PWV remote sensing systems.
\end{abstract}

\section{Introduction}

Water vapour (WV), a component of the Earth's atmosphere, plays a crucial role in global atmospheric radiation, energy equilibrium, and the hydrological cycle (Wang et al., 2007). Since the Global Positioning System (GPS) became fully operational in 1994, it has been possible to use GPS measurements to retrieve precipitable WV (PWV) information in the atmosphere (Duan et al., 1996). The main advantages of using GPS technique to derive PWV are its high quality, wide coverage, and all-time availability under all-weather conditions. These features are vital for meteorological applications of GPS such as the prediction of short-term rainstorms and rainy seasons (Song et al., 2003; Zhang et al., 2007) and the monitoring of severe weather events, including thunderstorms, hailstorms, strong winds, and hurricanes (Choy et al., 2001; Zhang et al., 2015).

PWV is defined as the equivalent height to a column of liquid water. GPS-derived PWV values above a given GPS station, i.e. GPS-PWV, are converted from the zenith tropospheric delay (ZTD) estimated from GPS measurements. The GPS-PWV can be used to compare different techniques of $\mathrm{WV}$ detection, such as radiosonde, $\mathrm{WV}$ radiometer, Moderate-Resolution Imaging Spectroradiometer (MODIS), and sun photometer (Yang et al., 1999; Li et al., 2003; Prasad and Singh, 2009; Kwon et al., 2010). It can also be used for evaluating improvements in numerical weather prediction (NWP) systems (Gutman and Benjamin, 2001; Song et al., 2004). Moreover, temporal and spatial variations in PWV can be precisely identified using GPS-PWV over GPS networks (Champollion et al., 2004; Jin and Luo, 2009; Van Baelen and Penide, 2009).

The GPS-derived ZTD (GPS-ZTD) generally consists of two components: the zenith hydrostatic delay (ZHD) and the zenith wet delay (ZWD). The ZWD is caused by WV in the atmosphere below $\sim 10 \mathrm{~km}$ height (Saastamoinen, 1972). Furthermore the ZWD can be converted to PWV by multiplying it with a dimensionless conversion factor. This factor is a function of atmospheric weighted mean temperature $\left(T_{\mathrm{m}}\right)$, 
as expressed below (Askne and Nordius, 1987; Davis et al., 1985; Jade et al., 2005).

$$
\begin{aligned}
\mathrm{PWV} & =\Pi \cdot(\mathrm{ZTD}-\mathrm{ZHD})=\Pi \cdot \mathrm{ZWD}, \\
T_{\mathrm{m}}= & \frac{10^{6}}{\rho_{\mathrm{w}} R_{\mathrm{v}}\left(k_{3} / T_{\mathrm{m}}+k_{2}^{\prime}\right)}, \\
T_{\mathrm{m}}= & \frac{\int_{h}^{h_{T}} \rho_{\mathrm{v}} \mathrm{d} z}{\int_{h}^{h_{T}} \rho_{\mathrm{v}} / T \mathrm{~d} z}
\end{aligned}
$$

where $\Pi$ is the conversion factor; $\rho_{\mathrm{W}}$ and $\rho_{\mathrm{v}}$ are the density of liquid water and $\mathrm{WV}$, respectively; $R_{\mathrm{V}}$ is the specific gas constant for water vapour; $k_{2}^{\prime}$ and $k_{3}$ are the atmospheric refractivity constants given in Bevis et al. (1994); and $T$ is the absolute temperature of the atmosphere in kelvin (K). Using the ideal gas law for water vapour, $\rho_{\mathrm{v}}$ can be written as $\rho_{\mathrm{v}}=e T / R_{\mathrm{V}}$, where $e$ is the $\mathrm{WV}$ pressure in $\mathrm{hPa}$ (Picard et al., 2008). The heights of the tropopause and the GPS station are $h_{T}$ and $h$, respectively. Note that both PWV and ZWD are in millimetres in Eqs. (1)-(3).

The $T_{\mathrm{m}}$ over a GPS station or at any given point can be accurately determined using a ray tracing method that takes profiles of atmospheric temperature and WV pressure. However, atmospheric profiles are almost impossible to obtain in real-time/near-real-time (RT/NRT) (Wang et al., 2016). Traditionally the following two alternatives have been used in practical applications: the Bevis formula $\left(T_{\mathrm{m}}=a+b \cdot T_{\mathrm{S}}\right.$ where $T_{\mathrm{s}}$ is the atmospheric temperature) and the empirical model (Bevis et al., 1994; Ross and Rosenfeld, 1997, 1999).

In the Bevis formula $T_{\mathrm{m}}=a+b \cdot T_{\mathrm{s}}$, the coefficients $(a$ and $b$ ) are season and location dependent and can be estimated from meteorological measurements (Wang et al., 2011; Bevis et al., 1992; Schueler et al., 2001; Mendes et al., 2000; Emardson and Derks, 2000). The root-mean-square error (RMSE) of $T_{\mathrm{m}}$ from the Bevis formula is $2-5 \mathrm{~K}$. Nevertheless, the Bevis formula becomes invalid when in situ temperature measurements are unavailable at some GPS stations, which could adversely affect the continuous operation of a RT/NRT GPS-PWV remote sensing system. Therefore, an empirical $T_{\mathrm{m}}$ model, fed only by coordinates of the site and the time, is essential for ground-based GPS atmospheric sounding. Although the accuracy of empirical models has been shown to be lower than that of the ray tracing method and the Bevis formula, it is still used as a practical alternative to calculate the $T_{\mathrm{m}}$ in RT/NRT if meteorological measurements are unavailable.

Table 1 summarises existing empirical $T_{\mathrm{m}}$ models developed in the last decade. The data source column presents the type and time span of the data used to develop the models: NCEP-DOE Atmospheric Model Intercomparison 2 data (NCEP2) released by National Centers for Environmental Prediction (NCEP), ERA-Interim data from the European Centre for Medium-range Weather Forecasts (ECMWF), and the Global Geodetic Observing System (GGOS) data generated from ECMWF reanalysis data.

Building upon the global pressure and temperature (GPT) model proposed by Böhm et al. (2007), Yao et al. (2012) developed the season-specific Global Weighted Mean Temperature (GWMT) model based on radiosonde data of 135 global stations in the period 2005-2009. The RMSE of $T_{\mathrm{m}}$ over the ground is around $4.6 \mathrm{~K}$. However, due to its poor performance in the southern Pacific Ocean, the coefficients were recalculated for an updated model - GTm-II using $T_{\mathrm{m}}$ over the ocean calculated from the Bevis formula, where $T_{\mathrm{s}}$ is derived from the GPT model (Yao et al., 2013). This GTmII model was further improved into GTm-III using GGOS surface $T_{\mathrm{m}}$ by taking semi-annual and diurnal variations of $T_{\mathrm{m}}$ into account (Yao et al., 2014a). In the later GWMTIV model, the $T_{\mathrm{m}}$ lapse rate is considered as a function of geodetic coordinates instead of a constant value adopted in the former models (He et al., 2013). In a study by Chen et al. (2014), the non-linear model in GTm-III was expressed into a linear one and developed it further into GTm_N. Unlike the spherical harmonics applied in GTm_N, Chen and Yao (2015) developed the GTm-X model based on the semiannual and diurnal variations in $T_{\mathrm{m}}$ with a global resolution of a $1^{\circ} \times 1^{\circ}$ geographical grid. More details for these three models can be found in Appendix B. Note that UNB3m and GPT2 $\mathrm{w}$ are not specific $T_{\mathrm{m}}$ models even though they can output $T_{\mathrm{m}}$ values (Leandro et al., 2008; Böhm et al., 2015). In addition, no comprehensive intercomparison with the same reference $T_{\mathrm{m}}$ has been carried out among existing empirical $T_{\mathrm{m}}$ models.

However, given that the diurnal variation and the lapse rate of $T_{\mathrm{m}}$ are either ill-modelled or neglected in most of these empirical models, this study presents a recent development towards an improved $T_{\mathrm{m}}$ model (i.e. GWMT-D). This paper is structured as follows. Section 2 reviews the data sets used for determination of $T_{\mathrm{m}}$ and validation of empirical $T_{\mathrm{m}}$ models. Section 3 presents the new model GWMT-D and its procedure of calculation. The performance of the new model GWMT-D is assessed against three other selected models using reference $T_{\mathrm{m}}$ derived from $2014 \mathrm{NCEP} 2$, radiosonde, and GGOS data in Sect. 4, followed by conclusions in Sect. 5 .

\section{The determination of $T_{\mathrm{m}}$}

Three data sets with various temporal and spatial resolutions are used to calculate $T_{\mathrm{m}}$ : NCEP2 reanalysis data, GGOS data, and radiosonde measurements. NCEP2 data in the period 2010-2013 are used to develop the new GWMT-D model, while all these three data sets in 2014 are used to evaluate GWMT-D as well as the other three selected empirical $T_{\mathrm{m}}$ models. 
Table 1. A list of the latest global empirical $T_{\mathrm{m}}$ models ${ }^{\mathrm{a}}$.

\begin{tabular}{|c|c|c|c|c|c|}
\hline Model name & Feature & Data source & $\begin{array}{c}\text { Input } \\
\text { variable }\end{array}$ & $\begin{array}{l}\text { Surface } T_{\mathrm{m}} \\
\text { error }(\mathrm{K})\end{array}$ & Reference \\
\hline UNB3m & Annual & $\begin{array}{c}\text { US Standard } \\
\text { Atmosphere Supplements }\end{array}$ & $\varphi, \theta$, DOY, $h$ & - & Leandro et al. (2008) \\
\hline GWMT & $\begin{array}{l}\text { Spherical } \\
\text { Harmonic }\end{array}$ & Radiosonde (2005-2009) & $\varphi$, DOY, $h$ & 4.6 & Yao et al. (2012) \\
\hline GTm-II & $\begin{array}{l}\text { Spherical } \\
\text { Harmonic }\end{array}$ & Radiosonde (2005-2009) & $\varphi$, DOY, $h$ & 4.0 & Yao et al. (2013) \\
\hline GTm-III & $\begin{array}{l}\text { Spherical } \\
\text { Harmonic }\end{array}$ & GGOS (2005-2011) & $\begin{array}{l}\theta, \text { DOY, } \\
\text { HOD, } h\end{array}$ & 4.2 & Yao et al. (2014a) \\
\hline GWMT-IV & $\begin{array}{l}\text { Spherical } \\
\text { Harmonic }\end{array}$ & NCEP2 (2005-2009) & $\varphi$, DOY, $h$ & $\sim 4.1$ & He et al. (2013) \\
\hline GTm_N & $\begin{array}{l}\text { Spherical } \\
\text { Harmonic }\end{array}$ & NCEP (2006-2012) & $\varphi$, DOY, $h$ & 3.38 & Chen et al. (2014) \\
\hline GTm_X & Grid & ERA-Interim (2007-2010) & $\varphi$, DOY, $h$ & $\sim 4.0$ & Chen and Yao (2015) \\
\hline GPT2w & Grid & ERA-Interim (2001-2010) & $\varphi$, DOY, $h$ & $<4.0^{*}$ & Böhm et al. (2015) \\
\hline
\end{tabular}

\subsection{NCEP2 data}

A state-of-the-art analysis and forecast system has been used to assimilate multi-source data since 1948 and the NCEP2 data set is an updated version from its former reanalysis data (available on www.esrl.noaa.gov/psd/data/gridded/data. ncep.reanalysis2.pressure.html) (Kanamitsu et al., 2002). The NCEP2 global reanalysis data set has a latitude and longitude grid resolution of $2.5^{\circ} \times 2.5^{\circ}$ at 17 different pressure layer from 1000 to $10 \mathrm{hPa}$ and also has a temporal resolution of $6 \mathrm{~h}$ (namely, at 00:00, 06:00, 12:00, 18:00 UTC). In this study, temperature, geopotential height, pressure, and humidity from NCEP2 data over the period of 2010-2014 are used for the development and validation of the new GWMT-D model.

\subsection{Radiosonde data}

Radiosondes released from ground-based stations can directly measure the atmospheric profiles. Radiosonde records from 585 global Integrated Global Radiosonde Archive (IGRA) stations (Fig. 1) in 2014 are utilised to validate the new GWMT-D model. They are retrieved from the upper-air archive at the website of University of Wyoming (available on http://weather.uwyo.edu/upperair/ sounding.html). The daily observations at a site usually consist of 1-4 radiosonde observations, containing pressure, temperature, geopotential height, dew point temperature, relative humidity $(\mathrm{RH})$, and mixing ratio at the surface, tropopause, and standard pressure levels (i.e. 1000, 925,
$850,700,600,500,400,300,250,200,150,100,70,50$, 30,20 , and $10 \mathrm{hPa}$ ) (Wang et al., 2005). $T_{\mathrm{m}}$ values are obtained through numerical integration (see Appendix A) under the assumption that the collected pressure, temperature, and humidity measurements are along the zenith direction, even though radiosonde balloons often drift away from the vertical direction, especially in windy conditions.

In addition, raw radiosonde measurements are rejected as outliers in the data preprocessing under the following conditions:

1. the height of the first data record in the profile is greater than $20 \mathrm{~m}$ above the ground;

2. the difference in height between two successive pressure levels is greater than $10 \mathrm{~km}$;

3. the gap between two successive atmospheric pressure levels is greater than $200 \mathrm{hPa}$;

4. the total number of valid radiosonde levels is less than 20 ;

5. the highest humidity level (at the pressure level of 200$350 \mathrm{hPa}$ ) is less than $\mu-4 \sigma$ (where $\mu$ and $\sigma$ are the mean height of the tropopause and its standard deviation) obtained from an empirical model (Liu, 2015);

6. the height of the last data record in the profile is lower than $20 \mathrm{~km}$. 


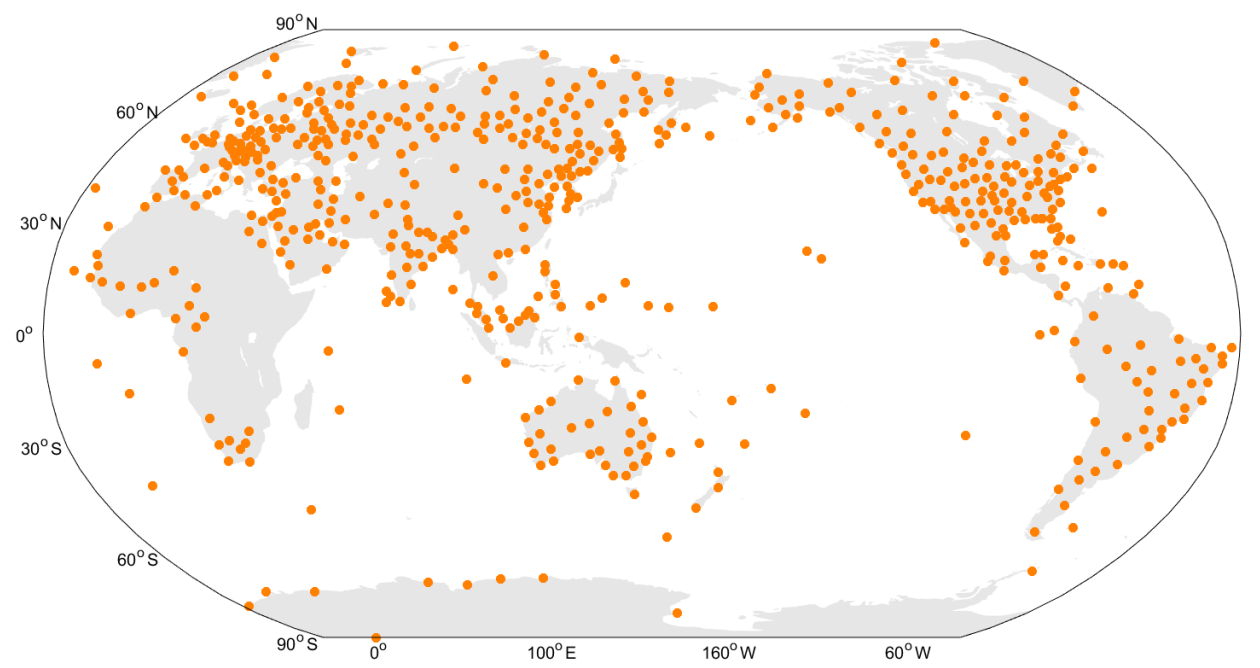

Figure 1. Distribution of the 585 radiosonde stations selected to validate the new GWMT-D model (only those data that pass a quality check are used).

\subsection{Surface $T_{\mathrm{m}}$ from GGOS Atmosphere}

In this study, global surface $T_{\mathrm{m}}$ values are used for the validation of the new GWMT-D model. GGOS Atmosphere provides the daily global surface $T_{\mathrm{m}}$ with a horizontal resolution of $2^{\circ} \times 2.5^{\circ}$ (latitude and longitude) at 00:00, 06:00, 12:00, and 18:00 UTC (available on http://ggosatm.hg.tuwien.ac.at/ DELAY/ETC/TMEAN/). This data set has been applied in the development of GTm-III and will be also used in the performance assessment of this study. Nevertheless, the discrepancies between these different data sets are noticeable and may affect the validation results, which will be shown in Sect. 4.

\section{GWMT-D model}

The NCEP2 data from the 4-year period 2010-2013 are employed to develop the new GWMT-D (D stands for diurnal variation) model. All global $T_{\mathrm{m}}$ values with a latitudinal and longitudinal grid resolution of $2.5^{\circ}$ at 17 pressure levels are first calculated (see Eq. 3). For more details of the calculation, refer to Appendix A. Note that the geopotential height in the radiosonde and NCEP2 data needs to be converted to ellipsoidal height (refer to Appendix A), which is simplified as "height" hereafter.

\subsection{Improvements in GWMT-D}

Compared with other empirical $T_{\mathrm{m}}$ models, the improvement achieved by the new GWMT-D model are the modelling of diurnal variation and lapse rate in $T_{\mathrm{m}}$. The $T_{\mathrm{m}}$ lapse rate in this paper is the decreasing rate of $T_{\mathrm{m}}$ (Bevis et al., 1994; Yao et al., 2012). The heights of 17 pressure levels in NECP2 data are time-variant. In order to investigate a time series of
$T_{\mathrm{m}}$ for a specific location, NCEP2-derived $T_{\mathrm{m}}$ at the pressure level for each grid points are first interpolated at four selected reference heights: $0,2,5$, and $9 \mathrm{~km}$. The spline interpolation is carried out in this procedure to avoid the Runge's phenomenon (Fornberg and Zuev, 2007). Also the $T_{\mathrm{m}}$ time series at each of the reference times (00:00, 06:00, 12:00, 18:00 UTC) of day for a specific reference location are assumed to follow a seasonal cycle:

$$
\begin{gathered}
T_{\mathrm{m}}(\mathrm{DOY})=\alpha_{1}+\alpha_{2} \cos \left(2 \pi \frac{\mathrm{DOY}}{365.25}\right)+\alpha_{3} \sin \left(2 \pi \frac{\mathrm{DOY}}{365.25}\right) \\
+\alpha_{4} \cos \left(4 \pi \frac{\mathrm{DOY}}{365.25}\right)+\alpha_{5} \sin \left(4 \pi \frac{\mathrm{DOY}}{365.25}\right)
\end{gathered}
$$

where DOY is the day of year, $\alpha_{1}$ is the annual mean value; $\alpha_{2}$ and $\alpha_{3}$ are the coefficients of the annual variation, and $\alpha_{4}$ and $\alpha_{5}$ are that of the semi-annual variation. Here the reference locations mean the geodetic coordinates of the grid points on the four reference height levels.

These coefficients are estimated from the time series of $T_{\mathrm{m}}$ values at the specific reference time using the leastsquares method. The new model is developed upon a fourdimensional (4-D) global $T_{\mathrm{m}}$ field with a resampled horizontal resolution of $5^{\circ} \times 5^{\circ}$ at the four reference height levels and the four reference times. The voxel-based feature of GWMT-D's coefficients is its primary difference from the other models.

\subsubsection{Diurnal variation}

Annual and semi-annual variations in a NCEP2-derived $T_{\mathrm{m}}$ time series for a reference location can be detected using the spectrum analysis (Chen et al., 2014). Although simple sine and cosine functions have been widely used to model the diurnal variations of $T_{\mathrm{m}}$, few studies have been conducted to 

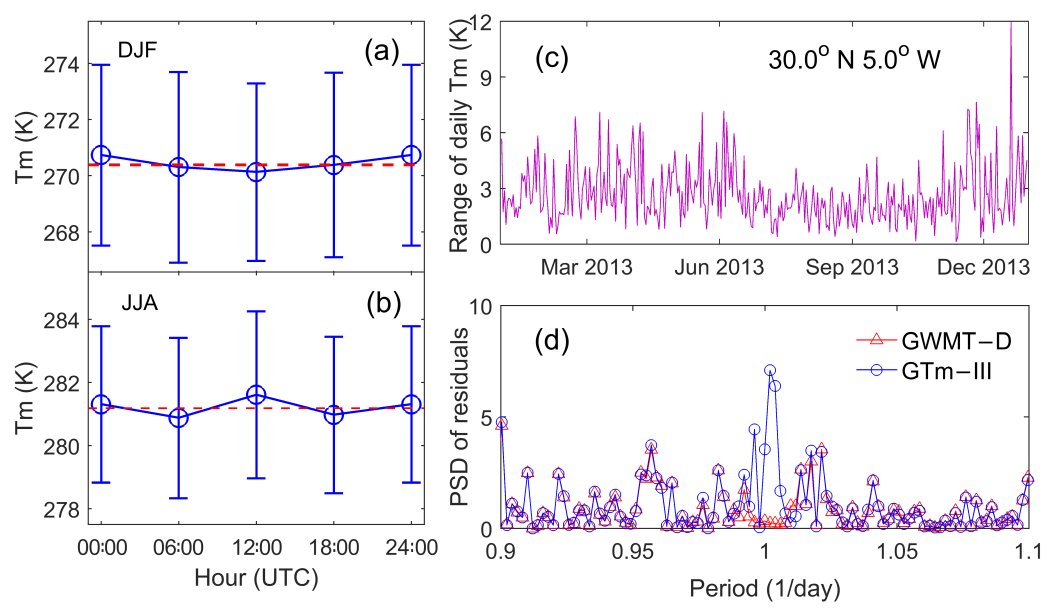

Figure 2. Statistical results of diurnal $T_{\mathrm{m}}$ (mean \pm standard deviation) at $2 \mathrm{~km}$ height and four reference times during (a) December-JanuaryFebruary (DJF) and (b) June-July-August (JJA) in 2013, (c) the range of daily $T_{\mathrm{m}}$ (max - min), and (d) power spectrum density (PSD) of $T_{\mathrm{m}}$ residuals.

analyse the periodic nature of the diurnal variation in $T_{\mathrm{m}}$. Diurnal variations in different seasons and locations are first investigated to study the voxel-based modelling process in GWMT-D.

Figure 2 shows an example of the diurnal variation at $2 \mathrm{~km}$ above the ground for $30^{\circ} \mathrm{N}, 5^{\circ} \mathrm{W}$. It clearly shows that, on the one hand, the diurnal variation in $T_{\mathrm{m}}$ is season and location dependent and is difficult to be modelled through simple trigonometric functions as used in the GTm-III model (see Appendix B). On the other hand, the plot of power spectrum density (PSD) in Fig. 2d shows that GWMT-D efficiently captures the diurnal variations in $T_{\mathrm{m}}$ but GTm-III does not. This study takes into account this feature by modelling $T_{\mathrm{m}}$ at each of the four reference times so that $T_{\mathrm{m}}$ values at any other times can be obtained by the spline interpolation.

\subsubsection{Vertical lapse rate of $T_{\mathrm{m}}$}

The $T_{\mathrm{m}}$ lapse rate along the vertical direction can be affected by several factors, e.g. the moisture content of air, atmospheric pressure and the surface height. Figure 3 illustrates the global distribution of annual mean $T_{\mathrm{m}}$ lapse rate in the height layer from the ground up to $2 \mathrm{~km}$ in 2013. It shows that global annual mean $T_{\mathrm{m}}$ lapse rate varies with latitude and land-sea distribution. Therefore, it is essential to consider season- and location-dependent $T_{\mathrm{m}}$ lapse rate in the development of empirical $T_{\mathrm{m}}$ models. More results can be found in Sect. 4.3.

Four specific reference height levels $(0,2,5$, and $9 \mathrm{~km})$ are selected covering most of the troposphere in the new GWMT-D model. All global $T_{\mathrm{m}}$ values on these reference heights are first calculated (see Eq. 3). Then $T_{\mathrm{m}}$ value for any other heights can be obtained by piecewise linear interpolating its two nearest height levels. This improvement is a distinguished feature of the new model in comparison with

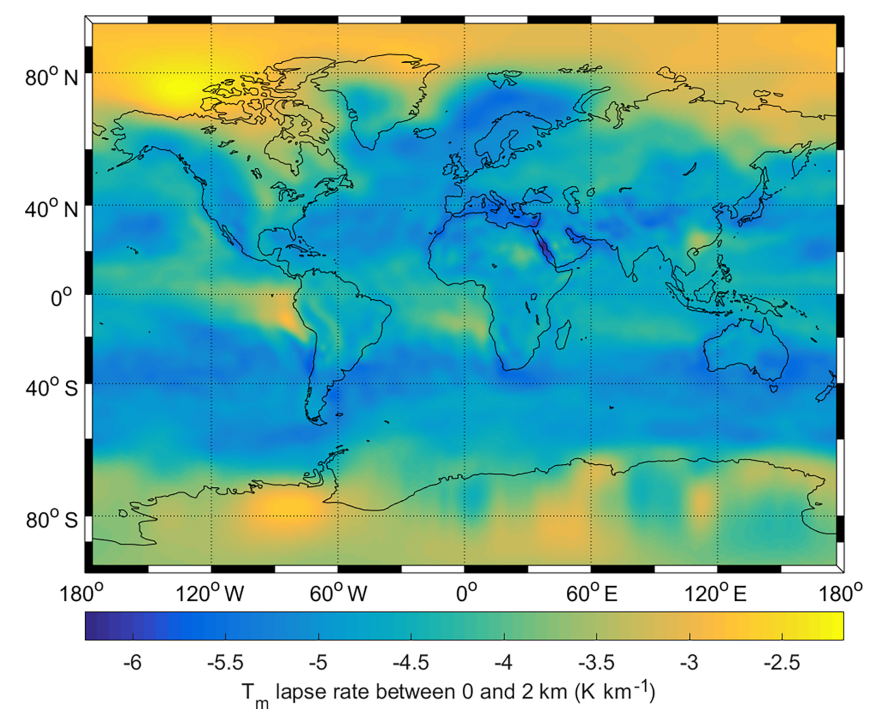

Figure 3. Global annual mean $T_{\mathrm{m}}$ lapse rate in the height interval $0-2 \mathrm{~km}$ from NCEP2 in 2013.

the aforementioned empirical models where a constant $T_{\mathrm{m}}$ lapse rate is adopted for the different heights over the globe. This step has been taken for each reference time.

\subsubsection{Data span used in $T_{\mathrm{m}}$ modelling}

Another important task is to determine the optimal length of reanalysis data required for the development of empirical $T_{\mathrm{m}}$ models. Long-term $T_{\mathrm{m}}$ data ( $>10$ years) over the globe can be used for climatological analysis, but the temporal correlation of $T_{\mathrm{m}}$ time series may be too weak to be considered in the $T_{\mathrm{m}}$ modelling process. However, a set of short-term $T_{\mathrm{m}}$ data ( $<1$ year) may be insufficiently for reliable results. 
Consequently, an optimal length of period needs to be investigated.

Different sets of coefficients of the GWMT-D are calculated using the NCEP2-derived $T_{\mathrm{m}}$ data for a period of 1 (2013) to 9 years (2005-2013). The GWMT-D with different sets of coefficients are compared with 1-year $T_{\mathrm{m}}$ time series at five pressure levels $(1000,925,850,700$, and $600 \mathrm{hPa}) \mathrm{de}-$ rived from NCEP2 data in 2014. Table 1 lists the statistical results of the comparison. In this research, the NCEP2 $T_{\mathrm{m}}$ time series from the 4-year period are adopted to develop the GWMT-D model for its best-fitting results (shown in bold fonts).

\subsection{The procedure to determine $T_{\mathrm{m}}$ using GWMT-D}

Assuming $T_{\mathrm{m}}$ is a function of the target location $(\varphi, \lambda, h)$, day of year (DOY), and UTC hour (HOD), the key steps of determining $T_{\mathrm{m}}$ in GWMT-D can be described as follows:

1. Two nearest reference height levels close to $h$, (see Fig. 4 in grey) and the other four vertical surfaces containing the eight voxels closest to $(\varphi, \lambda)$ are determined. Then $T_{\mathrm{m}}$ values for the reference times on the eight voxels are given by

$$
\begin{gathered}
T_{\mathrm{m}}\left(\varphi_{i}, \lambda_{j}, h_{l}, t_{k}\right)=\alpha_{1}\left(\varphi_{i}, \lambda_{j}, h_{l}, t_{k}\right) \\
+\alpha_{2}\left(\varphi_{i}, \lambda_{j}, h_{l}, t_{k}\right) \cos \left(2 \pi \frac{\mathrm{DOY}}{365.25}\right) \\
+\alpha_{3}\left(\varphi_{i}, \lambda_{j}, h_{l}, t_{k}\right) \sin \left(2 \pi \frac{\mathrm{DOY}}{365.25}\right) \\
+\alpha_{4}\left(\varphi_{i}, \lambda_{j}, h_{l}, t_{k}\right) \cos \left(4 \pi \frac{\mathrm{DOY}}{365.25}\right) \\
+\alpha_{5}\left(\varphi_{i}, \lambda_{j}, h_{l}, t_{k}\right) \sin \left(4 \pi \frac{\mathrm{DOY}}{365.25}\right),
\end{gathered}
$$

where $\varphi_{i}$ and $\lambda_{j}$ are the latitude and longitude of the vertex (at a $5^{\circ} \times 5^{\circ}$ resolution); $l(l=1,2,3,4)$ is the index of the reference height $h_{l}$ corresponding to $0,2,5$ or $9 \mathrm{~km}$, respectively; and $t_{k}(k=1,2, \ldots, 5)$ is the index of the reference time corresponding to 00:00, 06:00, 12:00, 18:00, and 24:0 UTC, respectively.

2. For each of the four reference time, a vertical interpolation is performed for the four grid points at the height of $h$ (four corners of the dashed rectangular in Fig. 4). At each grid point, $T_{\mathrm{m}}$ is linearly interpolated from the $T_{\mathrm{m}}$ values on the two nearest reference height levels $h_{l}$ and $h_{l+1}$ :

$$
\begin{aligned}
& T_{\mathrm{m}}\left(\varphi_{i}, \lambda_{j}, h\right)=T_{\mathrm{m}}\left(\varphi_{i}, \lambda_{j}, h_{l}\right) \\
& \quad+\frac{T_{\mathrm{m}}\left(\varphi_{i}, \lambda_{j}, h_{l+1}\right)-T_{\mathrm{m}}\left(\varphi_{i}, \lambda_{j}, h_{l}\right)}{h_{l+1}-h_{l}} \cdot\left(h-h_{l}\right) .
\end{aligned}
$$

3. The $T_{\mathrm{m}}$ values on the four corners are horizontally interpolated to obtain the $T_{\mathrm{m}}$ at the target point $(\varphi, \lambda, h)$ using

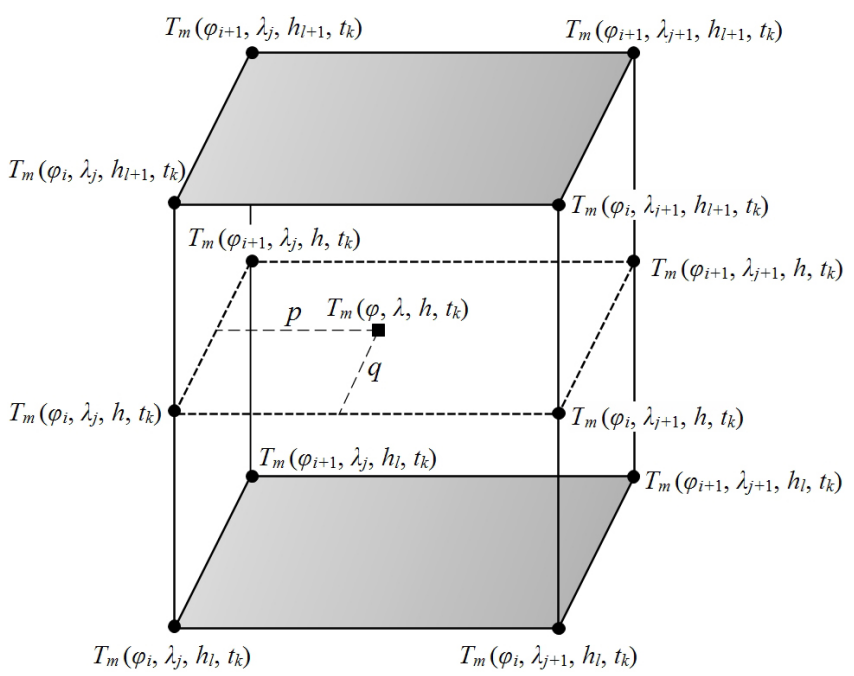

Figure 4. Spatial interpolation for the target point located at $(\varphi, \lambda$, $h$ ) using the $T_{\mathrm{m}}$ values at the eight closest voxels determined by the GWMT-D model. The first interpolation is for each of the four vertical edges of the box, and the second interpolation is on the 2-D plane at the height of the target point (the dashed rectangular).

$$
\begin{aligned}
& T_{\mathrm{m}}\left(\varphi_{i}, \lambda_{j}, h\right)=T_{\mathrm{m}}\left(\varphi_{i}, \lambda_{j}, h_{l}\right) \\
& \quad+\frac{T_{\mathrm{m}}\left(\varphi_{i}, \lambda_{j}, h_{l+1}\right)-T_{\mathrm{m}}\left(\varphi_{i}, \lambda_{j}, h_{l}\right)}{h_{l+1}-h_{l}} \cdot\left(h-h_{l}\right), \\
& p=\left(\lambda-\lambda_{j}\right) / 5, q=\left(\varphi-\varphi_{i}\right) / 5, \\
& \quad+p(1-q) T_{\mathrm{m}}\left(\varphi_{i}, \lambda_{j+1}, h\right) \\
& \quad+(1-p) q T_{\mathrm{m}}\left(\varphi_{i+1}, \lambda_{j}, h\right) \\
& \quad+p q T_{\mathrm{m}}\left(\varphi_{i+1}, \lambda_{j+1}, h\right) .
\end{aligned}
$$

Now $T_{\mathrm{m}}$ values of the target point are determined on the four reference times of the day (i.e. 00:00, 06:00, 12:00, and 18:00 UTC). All of notations in Eqs. (7) and (8) can be found in Fig. 4. The number "5" in Eq. (7) is the horizontal resolution of the new model.

4. After the aforementioned spatial interpolations, a spline interpolation in the time domain is carried out to find the $T_{\mathrm{m}}$ of the target location $(\varphi, \lambda, h)$ for the specific time of the day $t_{k}$ using the $T_{\mathrm{m}}$ values from the previous step.

\section{Validation of $T_{\mathrm{m}}$ models}

Different empirical $T_{\mathrm{m}}$ models (Table 1) are developed based on different data sets. The accuracies of these models claimed in relevant literature are referenced to different reference values (e.g. He et al., 2013; Chen et al., 2014; Yao 
Table 2. The global mean RMSE of various GWMT-D models built with different lengths of time periods (2005-2013) of NCEP2 data at five pressure levels (in K). The reference $T_{\mathrm{m}}$ are derived from NCEP2 data in 2014. The values inside square brackets are the minimum and maximum, and the fourth row (in bold) shows the best fitting results.

\begin{tabular}{cccccc}
\hline $\begin{array}{c}\text { Period length } \\
\text { (year) }\end{array}$ & $1000 \mathrm{hPa}$ & $925 \mathrm{hPa}$ & $850 \mathrm{hPa}$ & $700 \mathrm{hPa}$ & $600 \mathrm{hPa}$ \\
\hline 1 & $3.31[1.16,12.47]$ & $3.40[1.17,11.66]$ & $3.50[1.18,10.84]$ & $4.19[1.16,9.81]$ & $4.74[1.31,15.38]$ \\
2 & $3.24[1.19,12.07]$ & $3.32[1.17,11.24]$ & $3.42[1.18,10.40]$ & $4.13[1.14,9.31]$ & $4.68[1.30,14.61]$ \\
3 & $3.23[1.18,12.33]$ & $3.32[1.19,11.48]$ & $3.43[1.21,10.61]$ & $4.13[1.14,9.47]$ & $4.67[1.28,13.84]$ \\
$\mathbf{4}$ & $\mathbf{3 . 2 2}[\mathbf{1 . 1 5 , 1 1 . 9 6}]$ & $\mathbf{3 . 3 2}[\mathbf{1 . 1 4}, \mathbf{1 1 . 1 4}]$ & $\mathbf{3 . 4 2}[\mathbf{1 . 1 8}, \mathbf{1 0 . 3 4}]$ & $\mathbf{4 . 1 3}[\mathbf{1 . 1 4 , 9 . 2 8}]$ & $\mathbf{4 . 6 7}[\mathbf{1 . 2 7}, \mathbf{1 1 . 5 4}]$ \\
5 & $3.22[1.18,12.13]$ & $3.31[1.18,11.29]$ & $3.42[1.18,10.45]$ & $4.12[1.13,9.37]$ & $4.66[2.10,11.75]$ \\
6 & $3.22[1.17,12.02]$ & $3.31[1.19,11.20]$ & $3.42[1.21,10.37]$ & $4.12[1.14,9.29]$ & $4.66[2.10,11.75]$ \\
7 & $3.22[1.16,12.13]$ & $3.31[1.19,11.30]$ & $3.41[1.21,10.47]$ & $4.11[1.14,9.41]$ & $4.66[2.10,13.80]$ \\
8 & $3.22[1.20,12.16]$ & $3.31[1.19,11.33]$ & $3.41[1.21,10.50]$ & $4.11[1.15,9.43]$ & $4.66[1.79,12.43]$ \\
9 & $3.22[1.20,12.28]$ & $3.31[1.19,11.42]$ & $3.41[1.21,10.56]$ & $4.11[1.15,9.48]$ & $4.66[1.27,11.55]$ \\
\hline
\end{tabular}
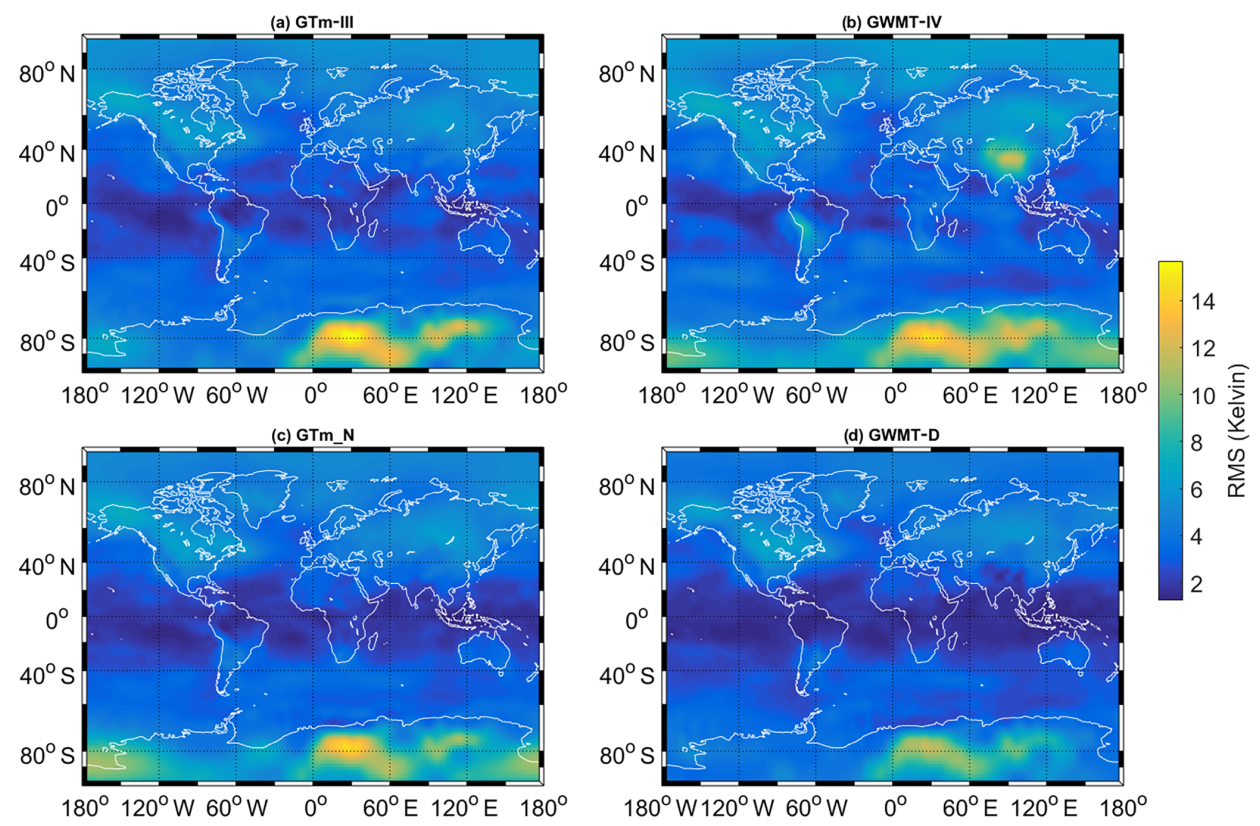

Figure 5. The global RMSE distribution of the differences between the $T_{\mathrm{m}}$ derived from each model and the NCEP2 data on pressure level of $925 \mathrm{hPa}$ in 2014.

et al., 2014a). Consequently, cross comparisons of these accuracy values for their performance may not be appropriate. In this study, the performance of three selected empirical $T_{\mathrm{m}}$ models and the new GWMT-D model is assessed using the same reference $T_{\mathrm{m}}$ values derived from NCEP2, GGOS, and radiosonde data sets.

Due to the fact that GTm_X is unavailable to the public and GWMT and GTm-II have been proven inferior to GTm-III, GWMT-IV, and GTm_N, only GTm-III, GWMTIV, GTm_N, and the new GWMT-D model are assessed. The methodologies for obtaining $T_{\mathrm{m}}$ from NCEP2 radiosonde data sets are given in Appendix A. The two statistical quantities used to measure the performance of these models are bias and RMSE, which are calculated by

$$
\begin{aligned}
& \text { Bias }=\frac{1}{N} \sum_{i=1}^{N}\left(T_{\mathrm{m}}^{C_{i}}-T_{\mathrm{m}}^{i}\right), \\
& \mathrm{RMSE}=\sqrt{\frac{1}{N} \sum_{i=1}^{N}\left(T_{\mathrm{m}}^{C_{i}}-T_{\mathrm{m}}^{i}\right)^{2},}
\end{aligned}
$$

where $T_{\mathrm{m}}^{C_{i}}$ and $T_{\mathrm{m}}^{i}$ are the $T_{\mathrm{m}}$ values from the models and the reference, respectively, and $N$ is the number of the samples.

\subsection{Comparison with NCEP2 data}

The globally mean biases and RMSEs of the differences between NCEP2-derived and model-derived $T_{\mathrm{m}}$ at all global grid points are summarised in Table 3. Only the results of pressure levels of $925 \mathrm{hPa}(\sim 0.6 \mathrm{~km})$ and $600 \mathrm{hPa}(\sim 5 \mathrm{~km})$ 
Table 3. The globally mean biases and RMSEs of the differences between the $T_{\mathrm{m}}$ (in $\mathrm{K}$ ) derived from four empirical models and 2014 NCEP2 data on pressure levels of 925 and $600 \mathrm{hPa}$. Values within square brackets are the minimum and maximum, and the $\%$ column is the percentage of those global grids with a value $\leq 5 \mathrm{~K}$.

\begin{tabular}{llrrrr}
\hline Pressure level & Model & Bias & $\%$ & RMSE & $\%$ \\
\hline \multirow{4}{*}{$925 \mathrm{hPa}$} & GTm-III & $-1.31[-5.19,9.63]$ & 98.0 & $3.91[1.26,15.38]$ & 77.1 \\
& GWMT-IV & $-1.89[-11.40,4.77]$ & 96.2 & $4.36[1.36,14.61]$ & 70.3 \\
& GTm_N & $-1.25[-8.53,9.18]$ & 97.1 & $3.84[1.16,13.84]$ & 77.4 \\
& GWMT-D & $-0.03[-2.50,4.62]$ & 100 & $3.32[1.14,11.14]$ & 91.1 \\
\hline \multirow{4}{*}{$600 \mathrm{hPa}$} & GTm-III & $-1.25[-9.30,4.92]$ & 89.4 & $5.63[2.10,11.75]$ & 33.2 \\
& GWMT-IV & $-5.83[1.69,12.35]$ & 38.4 & $7.28[2.10,13.80]$ & 13.7 \\
& GTm_N & $2.65[-9.10,8.81]$ & 72.9 & $6.38[1.79,12.43]$ & 26.0 \\
& GWMT-D & $0.03[-2.48,3.28]$ & 100 & $4.67[1.27,11.54]$ & 58.3 \\
\hline
\end{tabular}
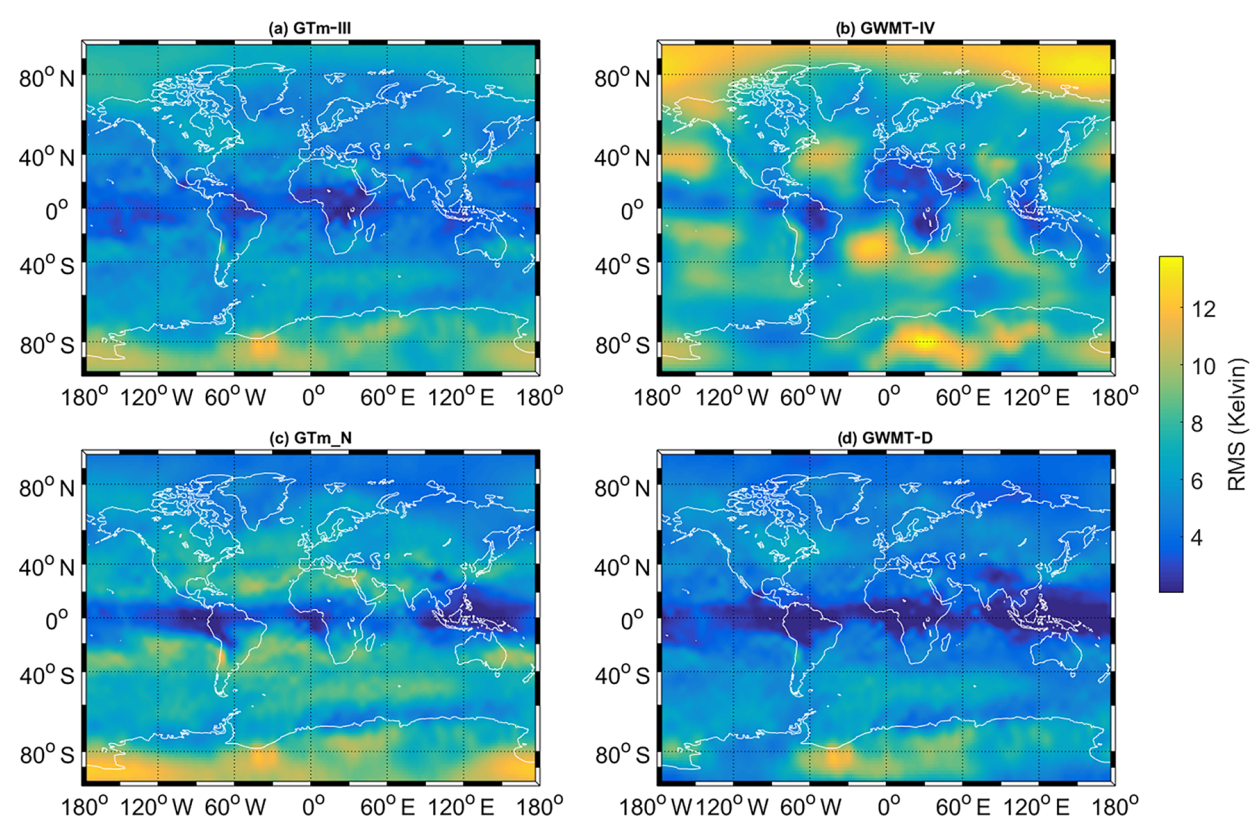

Figure 6. The global RMSE distribution of the differences between the $T_{\mathrm{m}}$ derived from each model and the NCEP 2 data on pressure level of $600 \mathrm{hPa}$ in 2014.

are given since similar results can be obtained from the new GWMT-D model on the other pressure levels less than $600 \mathrm{hPa}$ (refer to Table 2). One can find from Table 3 that GWMT-D significantly outperforms all the other three empirical models.

Figures 5-6 illustrate the distribution of the RMSE (not the mean RMSE of all grid points listed in Table 3) of the differences between the $T_{\mathrm{m}}$ derived from the models and the NCEP2 data in 2014 on two pressure levels. Figures 5d and $6 \mathrm{~d}$ present the best agreement for GWMT-D over the globe. On the pressure level of $925 \mathrm{hPa}$, more than $91 \%$ of the grid points had RMSE less than $5 \mathrm{~K}$, compared with $77 \%$ from GTm_N and GTm-III, and less than $71 \%$ from GWMT-IV. Whilst on the $600 \mathrm{hPa}$ level, GWMT-IV is worse, especially in the Arctic Circle. The RMSE values of GWMT-D ranged from $1.27 \mathrm{~K}$ to $11.55 \mathrm{~K}$, outperforming the other three mod- els with a global average RMSE of only $4.73 \mathrm{~K}$ and an approximately $25 \%$ improvement over the other models.

It is worth pointing out that all these four models have relatively low RMSE values near the tropical areas, and all have a similar performance globally except for the Antarctic. This finding is consistent with recent studies, (e.g. He et al., 2013; Chen et al., 2014; Yao et al., 2014a). It may be explained by the fact that the $T_{\mathrm{m}}$ on the pressure levels under the terrain of Antarctica $(\sim 6 \mathrm{~km})$ may contain large systematic biases caused by the extrapolation of actual meteorological records.

\subsection{Comparison with GGOS data}

The GGOS surface grid $T_{\mathrm{m}}$ data in 2014 are used as the reference in this section to evaluate the performance of the four models. The statistical results of the four selected models are 
Table 4. Global statistics of the differences between the surface $T_{\mathrm{m}}$ derived from four models and GGOS data in 2014 (in K).

\begin{tabular}{lrrrr}
\hline Model & Bias & $\%$ & RMSE & $\%$ \\
\hline GTm-III & $-0.02[-4.44,4.93]$ & 100 & $3.29[0.98,6.62]$ & 92.3 \\
GWMT-IV & $-0.88[-20.05,13.61]$ & 92.5 & $3.95[0.91,20.37]$ & 76.4 \\
GTm_N & $-0.27[-7.07,10.09]$ & 98.2 & $3.70[1.08,10.66]$ & 83.8 \\
GWMT-D & $1.20[-1.48,6.23]$ & 99.5 & $3.54[0.83,7.51]$ & 86.2 \\
\hline
\end{tabular}
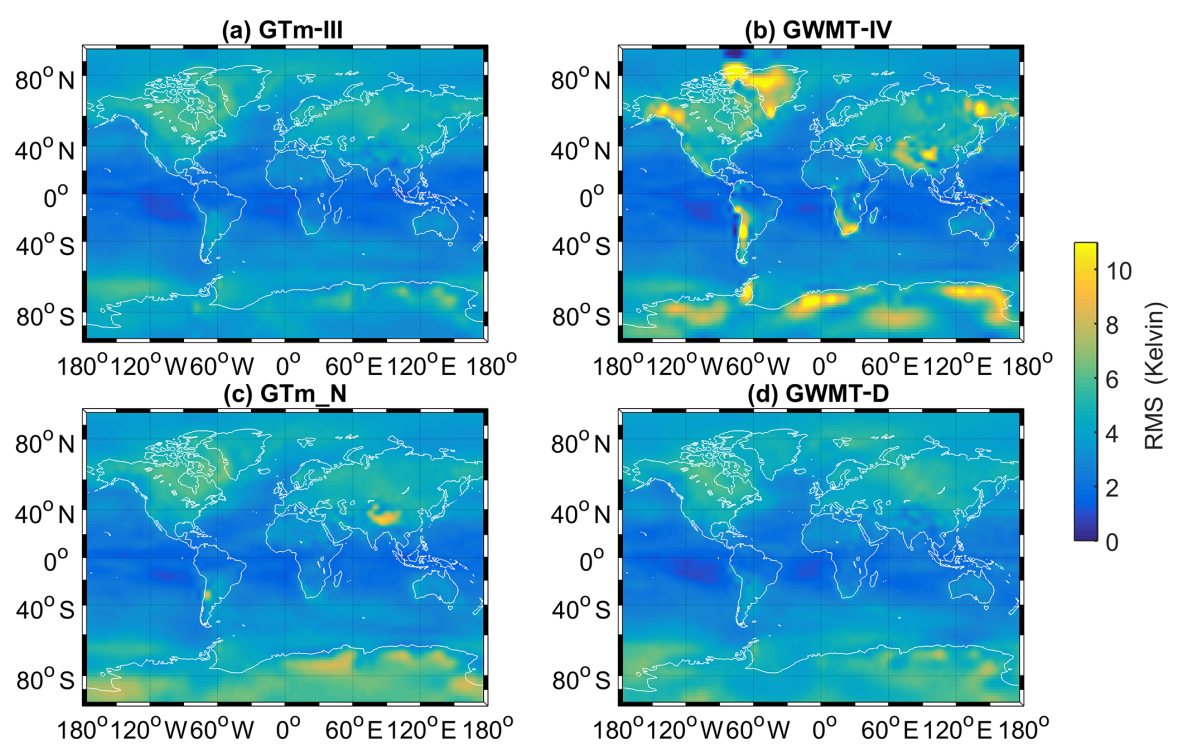

Figure 7. The global RMSE distribution of the differences between surface $T_{\mathrm{m}}$ derived from each model and GGOS data in 2014 .

shown in Table 4 and Fig. 7. The GTm-III performed the best this time because the GGOS Atmosphere data derived from ECMWF reanalysis data are used in the development of the GTm-III. From Table 3, GWMT-D is almost unbiased while the GTm-III showed a bias of -1.25 to $-1.31 \mathrm{~K}$ in comparison with the NCEP2-based $T_{\mathrm{m}}$. In contrast, a bias of about $+1.2 \mathrm{~K}$ (warmer) compared to the GGOS-based $T_{\mathrm{m}}$ is found with GWMT-D (see Table 4). This discrepancy of $1.2 \mathrm{~K}$ between the NCEP2-derived and GGOS-derived $T_{\mathrm{m}}$ may result from differences of NWP systems, e.g. different observations, physical models, data assimilation processes, and boundary conditions (Buizza et al., 2005).

Nevertheless, the good performance of GWMT-D indicates that the modelling method of $T_{\mathrm{m}}$ can significantly improve the model's accuracy. Figure $7 d$ illustrates that GWMT-D has RMSE values of less than $6 \mathrm{~K}$ at most grids, except the areas in the Antarctic, northeast North America, and Middle East (6-10 K).

\subsection{Comparison with radiosonde data}

These four empirical $T_{\mathrm{m}}$ models of interest are also evaluated using independent measurements (i.e. radiosonde). A number of comparisons are carried out in this section:
1. Surface $T_{\mathrm{m}}$ values calculated from radiosonde measurements are used as the reference to compare with various model-derived surface $T_{\mathrm{m}}$.

2. $T_{\mathrm{m}}$ derived from the GWMT-D and three other selected empirical models is compared with radiosondederived $T_{\mathrm{m}}$ to investigate models' performance in different heights.

3. The accuracy of the $T_{\mathrm{m}}$ models in different seasons is also investigated.

Figure 8 illustrates the RMSE of model-derived surface $T_{\mathrm{m}}$ in 2014 at the 585 selected radiosonde stations. The spatial (horizontal) variation in the accuracy of these models can be seen from this figure. An accuracy of better than $8 \mathrm{~K}$ has been achieved at most stations for the GWMT-D (Fig. 8d) and a similar accuracy can be achieved by the GTm_N as well (Fig. 8c). These two models outperformed the other two models, GTm-III and GWMT-IV, especially in the Middle East, Siberia, and South Africa regions.

Figure 9 shows the histogram of the difference (i.e. modelderived $T_{\mathrm{m}}$ minus radiosonde-derived $T_{\mathrm{m}}$ ) at all heights from 0 to $9 \mathrm{~km}$ in terms of the mean, standard deviation, median, and mode values. As one of the new trials in this study, we use mode and median values to estimate the sample bias. The 

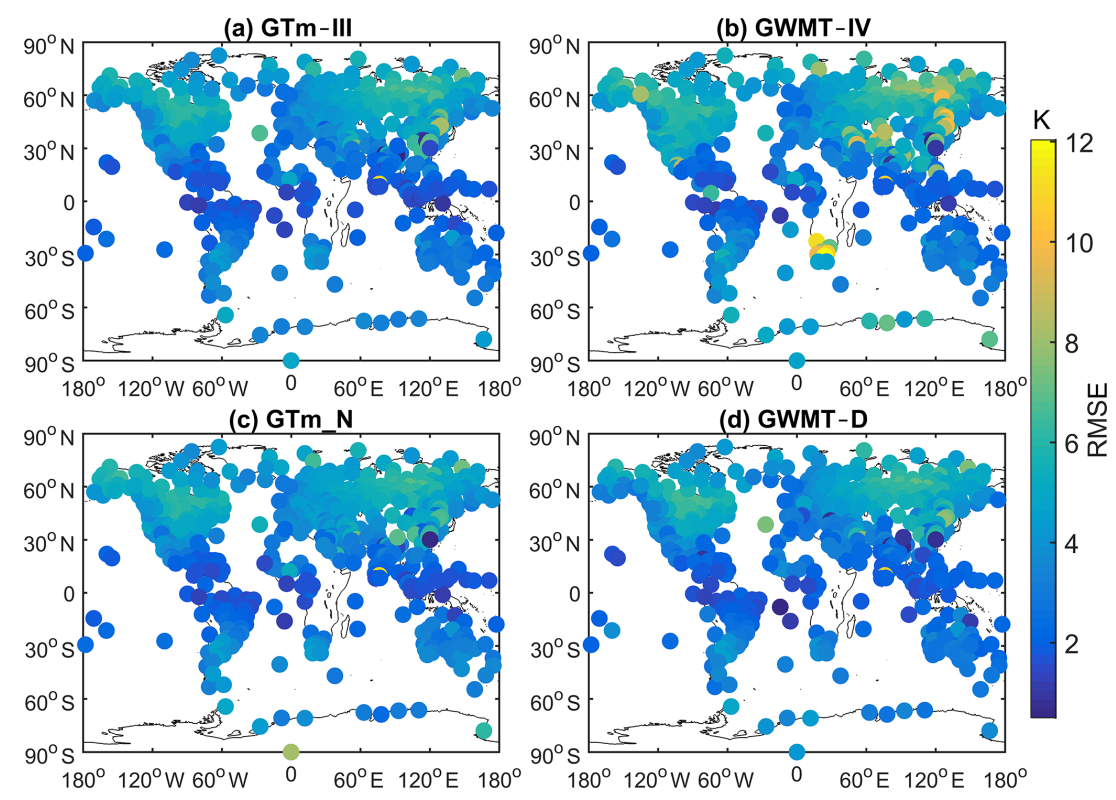

Figure 8. RMSE of model-derived surface $T_{\mathrm{m}}$ in 2014 at 585 global radiosonde sites.

Table 5. Statistics of the differences between model-derived and radiosonde-derived $T_{\mathrm{m}}$ in various height intervals for the year 2014 at 585 global radiosonde sites (in $\mathrm{K}$ ). The \% column in this table is the percentage of radiosonde records within the height interval in that of all height intervals.

\begin{tabular}{crrrrr}
\hline Height $(\mathrm{km})$ & $\%$ & $\begin{array}{r}\text { GWMT-D } \\
\text { bias (RMSE) }\end{array}$ & $\begin{array}{r}\text { GTm_N } \\
\text { bias (RMSE) }\end{array}$ & $\begin{array}{r}\text { GWMT-IV } \\
\text { bias (RMSE) }\end{array}$ & $\begin{array}{r}\text { GTm-III } \\
\text { bias (RMSE) }\end{array}$ \\
\hline$<2$ & 30.1 & $0.52(4.42)$ & $-0.39(4.50)$ & $-3.21(5.20)$ & $-0.73(4.48)$ \\
$2-5$ & 34.1 & $0.94(4.67)$ & $3.23(6.00)$ & $-8.18(10.11)$ & $3.23(4.82)$ \\
$5-9$ & 35.8 & $0.51(4.50)$ & $9.83(11.55)$ & $-14.53(18.33)$ & $9.83(6.50)$ \\
\hline
\end{tabular}

main advantage of using mode and median values is that they are more robust than the arithmetic mean value, especially in skewed distributions (see Fig. 9b and c). As a result, a warm (cold) bias of $3.8 \mathrm{~K}(-4.4 \mathrm{~K})$ can be found in the GTm_N (GWMT-IV). The histograms of both GTm-III and GWMTD (Fig. 9a and d) are normally distributed and the GWMT-D is slightly better than the GTm-III.

The entire radiosonde-derived $T_{\mathrm{m}}$ is grouped into three height intervals $0-2,2-5$, and $5-9 \mathrm{~km}$ according to their station heights. The accuracy comparisons between the GWMT$\mathrm{D}$ and other models in different height intervals are listed in Table 5. It can be concluded that the accuracies of all the models except for the GWMT-D are significantly degraded with the increase of the height of the site. In contrast, it shows that the accuracy of GWMT-D is nearly stable in three different height ranges. Compared with the GTm_N model, the better performance of GTm-III may result from the fact that GGOS $T_{\mathrm{m}}$, which was derived from ECMWF reanalysis data, is more consistent with the radiosonde data than the NCEPderived $T_{\mathrm{m}}$. The RMSE values of GWMT-D, GTm-III, and GTm_N are plotted in the Fig. 10 as a function of height relative to the ground surface in order to reveal the represen- tative effect of terrain on the models. The GWMT-D model's RMSEs are in the range of 4-5 K, while the other two models have large RMSE values at high altitudes. It is noted that the GWMT-IV model is excluded due to its poorer performance shown in Table 5. It shows that the accuracy of GWMT-D is better than $5 \mathrm{~K}$, even at the top of the troposphere.

Figure 11 shows the monthly or seasonal performance of these four selected models. The monthly-mean RMSEs of all the models vary with month (or season) and only the GTm_N shows a variation pattern opposite to that of the other three models. The GWMT-D and GWMT-III present very similar results in both pattern of variation and monthly-mean RMSEs. The GWMT-IV performs the worst and GWMT-D performs the best among all these four models.

\subsection{Impact of $T_{\mathrm{m}}$ on GPS-derived PWV}

The purpose of determining $T_{\mathrm{m}}$ is to convert the ZWD of GPS signals to PWV. From Eq. (1), the relationship of the RMSEs between $T_{\mathrm{m}}$ and PWV can be obtained as 

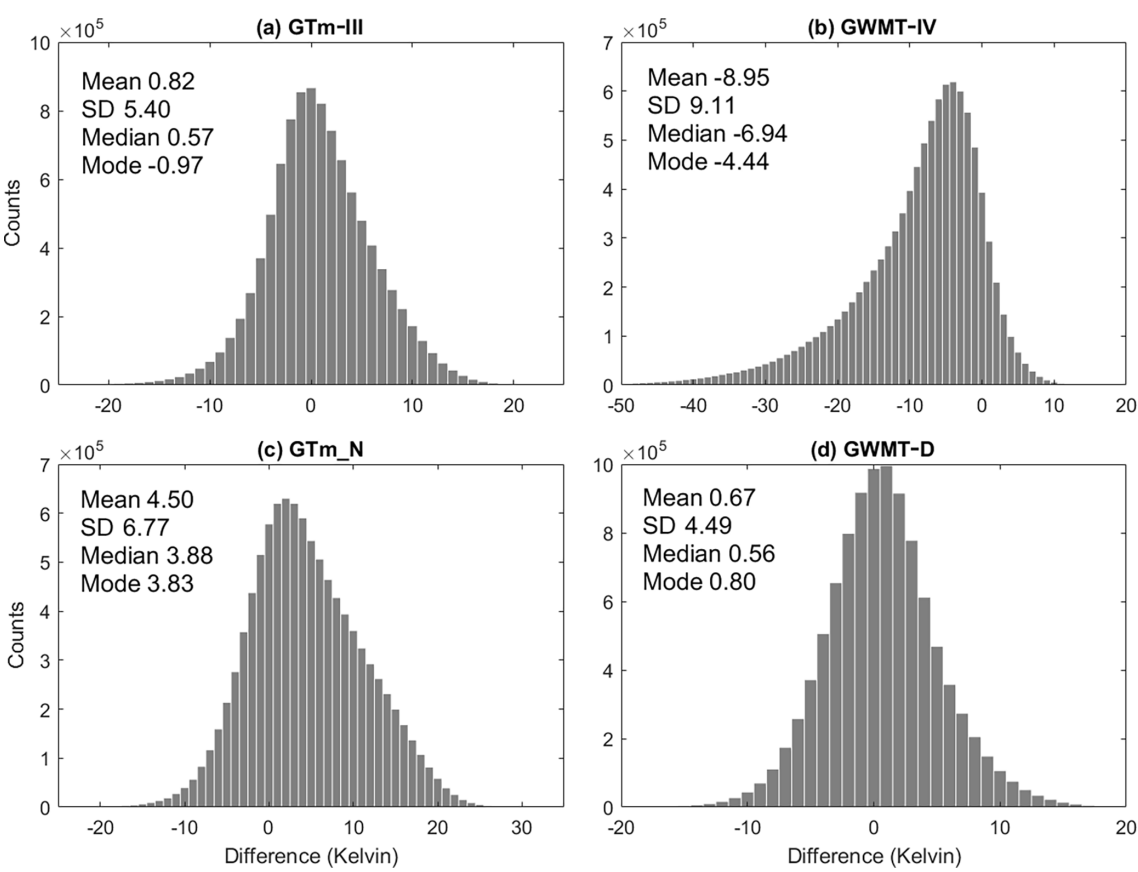

Figure 9. Histogram of model-derived $T_{\mathrm{m}}$ minus radiosonde-derived $T_{\mathrm{m}}$ in 2014 at different heights.

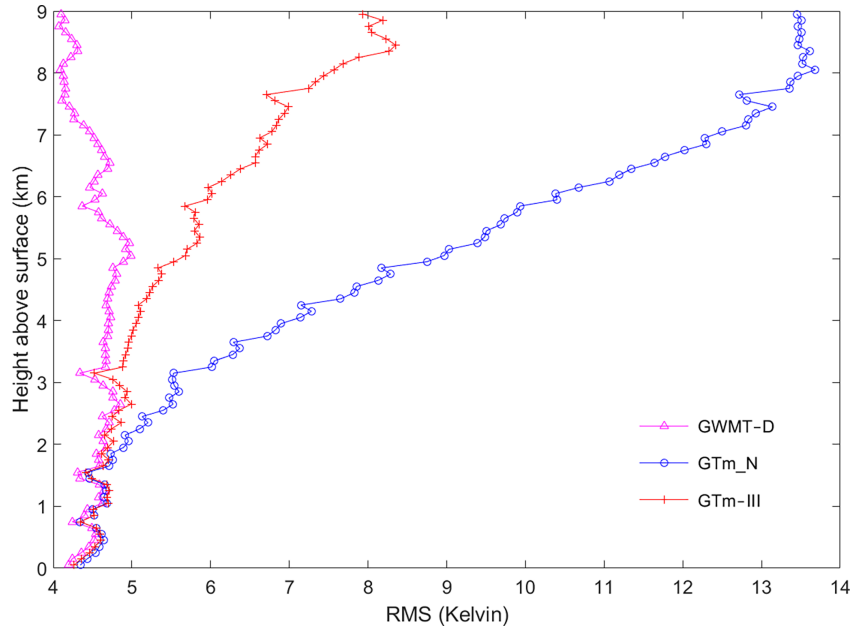

Figure 10. RMSE profile of the $T_{\mathrm{m}}$ from GTm-III, GTm_N, and GWMT-D models. The reference $T_{\mathrm{m}}$ values are derived from records of 585 radiosonde sites in 2014.

$$
\begin{aligned}
\frac{\mathrm{RMSE}_{\mathrm{PWV}}}{\mathrm{PWV}} & =\frac{\mathrm{RMSE}_{\Pi}}{\Pi}=\frac{k_{3} \mathrm{RMSE}_{T_{\mathrm{m}}}}{\left(k_{3} / T_{\mathrm{m}}+k_{2}^{\prime}\right) T_{\mathrm{m}}^{2}} \\
& =\frac{k_{3}}{\left(k_{3} / T_{\mathrm{m}}+k_{2}^{\prime}\right) T_{\mathrm{m}}} \cdot \frac{\operatorname{RMSE}_{T_{\mathrm{m}}}}{T_{\mathrm{m}}},
\end{aligned}
$$

where the three RMSEs are defined for the differences between observed and true values (more details see Appendix C) and the relative error of PWV can be defined as $\mathrm{RMSE}_{\mathrm{PWV}} / \mathrm{PWV}$ here.
Figure 12 illustrates the global distribution of both RMSE $_{\mathrm{PWV}}$ and RMSE $\mathrm{PWV}_{\mathrm{PWV}}$ obtained from Eq. (11) and radiosonde data in 2014. The value of $\mathrm{RMSE}_{T_{\mathrm{m}}}$ is obtained from Sect. 4.3 and PWV and $T_{\mathrm{m}}$ are set to annual mean values. Some radiosonde stations have been removed with insufficient observations or near the polar areas. As we can see the global mean values of RMSEPwV and RMSEPwV/PWV are around $0.25 \mathrm{~mm}$ and $1.3 \%$, respectively.

\section{Conclusion and discussion}

$T_{\mathrm{m}}$ is a critical parameter in PWV detection using the GPS atmospheric sounding technique. Robust empirical $T_{\mathrm{m}}$ models are required as a practical alternative in RT/NRT PWV remote sensing systems, especially when in situ meteorological measurements cannot be obtained. The accuracies of the existing empirical $T_{\mathrm{m}}$ models are limited by the ill-modelling or neglect of global lapse rate and diurnal fluctuations in $T_{\mathrm{m}}$. Therefore, a new voxel-based $T_{\mathrm{m}}$ model, namely GWMT$\mathrm{D}$, is developed in this study using global NCEP2 data from 2010 to 2013. The voxel-based modelling method effectively captures diurnal variations and lapse rates in $T_{\mathrm{m}}$.

Moreover, comprehensive comparisons with GTm-III, GWMT-IV, and GTm_N show that GWMT-D is unbiased and can achieve a RMSE accuracy of 4-5 K for different seasons and locations. The improvement of the new model is around $25 \%$ over the other three models when using NCEP2and radiosonde-derived $T_{\mathrm{m}}$ as reference. Comparisons with GGOS surface $T_{\mathrm{m}}$ show that GWMT-D's accuracy is slightly worse than that of GTm-III with a bias of $\sim 1.2 \mathrm{~K}$, possi- 


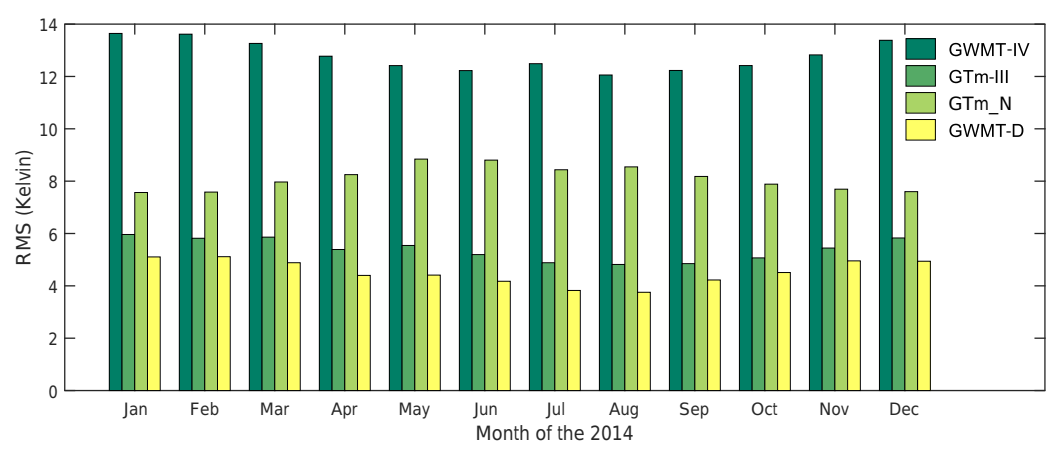

Figure 11. Monthly-mean RMSE of the $T_{\mathrm{m}}$ from the four models and reference values is global radiosonde-derived $T_{\mathrm{m}}$ in 2014 .
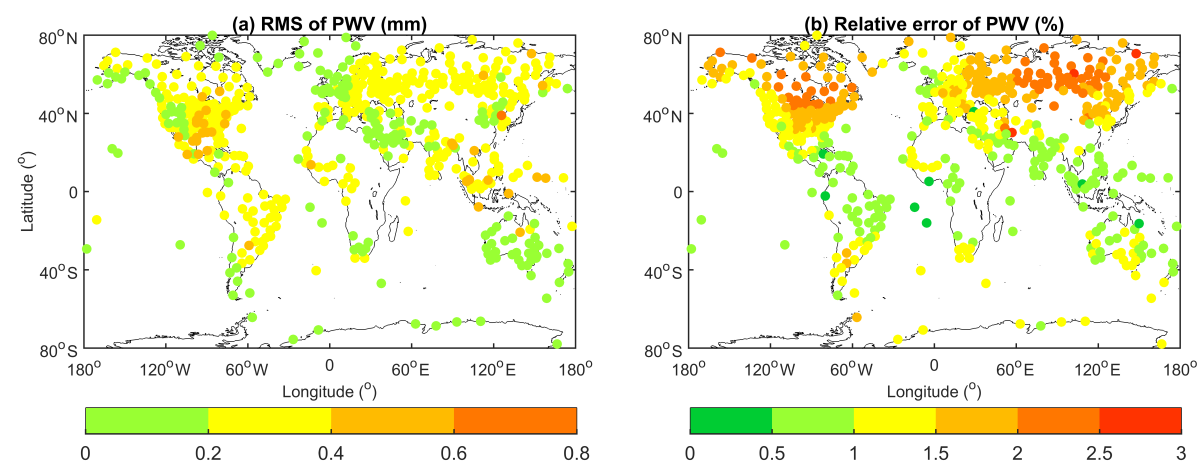

Figure 12. The theoretical RMSE (a) and relative error (b) of PWV resulting from the GWMT-D model using radiosonde observations in 2014.

bly due to the systematic difference between NCEP2 and ECMWF reanalysis data. This difference is significant, especially for the Antarctic. These comparisons also confirm that the piecewise linear interpolation of $T_{\mathrm{m}}$ used in GWMT-D is better than the direct modelling of $T_{\mathrm{m}}$ lapse rate in GWMTIV and the constant-value method in GTm-III and GTm_N. An approximate $0.3 \mathrm{~mm}$ global mean RMSE in PWV read as $1.3 \%$ relative error will be brought about by GWMT-D for ground stations.

It is suggested that the sets of coefficient for empirical $T_{\mathrm{m}}$ models (e.g. GWMT-D) need to be redetermined regularly using state-of-the-art data sets with appropriate length of time periods. The new GWMT-D model is an essential alternative $T_{\mathrm{m}}$ determination method to RT/NRT GPS PWV remote sensing system. The continuous operation of this system can be maintained even if in situ meteorological measurements on the GPS station are unavailable. Further inter- comparisons are recommended between empirical $T_{\mathrm{m}}$ models and other measurements over the ocean (for instance with the Constellation Observation System of Meteorology, Ionosphere, and Climate, COSMIC), since radiosonde measurements used in this study are mainly collected over the land. An optimal integral approach for the determination of $T_{\mathrm{m}}$ and quantification of the stochastic characteristics of $T_{\mathrm{m}}$ time series are the main focus of our future work.

Data availability. NCEP2: http://www.esrl.noaa.gov/psd/data/ gridded/data.ncep.reanalysis2.pressure.html.

Radiosonde: http://weather.uwyo.edu/upperair/sounding.html. GGOS: http://ggosatm.hg.tuwien.ac.at/DELAY/ETC/TMEAN/. 


\section{Appendix A: Determination of $T_{m}$ and water vapour pressure}

This appendix presents the calculation of $T_{\mathrm{m}}$ and water vapour pressure from layered meteorological data (e.g. reanalysis and radiosonde). The numerical integration in the Eq. (3) can be approximated as

$$
T_{\mathrm{m}} \approx \frac{\sum_{i=1}^{N}\left(\frac{e_{i}}{T_{i}}+\frac{e_{i+1}}{T_{i+1}}\right) \frac{\Delta z_{i}}{2}}{\sum_{i=1}^{N}\left(\frac{e_{i}}{T_{i}^{2}}+\frac{e_{i+1}}{T_{i+1}^{2}}\right) \frac{\Delta z_{i}}{2}},
$$

where $e_{i}$ and $e_{i+1}$ are the water vapour pressure and $T_{i}$ and $T_{i+1}$ are the temperature on the lower and upper boundary of the $i$ th layer of the atmosphere, $\Delta z_{i}$ is the thickness of the $i$ th layer, and $N$ is the total number of layers.

Note that the height used in NCEP2 and radiosonde data is the geopotential height, which is widely used in meteorology, whilst the height used in the Eq. (A1) is a geometric height. The equations for the conversion of a geopotential height to a geometric height (ellipsoidal height) are (Ge, 2006)

$$
\begin{aligned}
& h=\frac{R_{\mathrm{e}}(\varphi) \cdot H}{\frac{g(\varphi)}{g_{0}} R_{\mathrm{e}}(\varphi)-H}, \\
& g(\varphi)=9.80620\left(1-2.6442 \times 10^{-3} \cos 2 \varphi\right. \\
& \left.\quad+5.8 \times 10^{-6} \cos ^{2} 2 \varphi\right), \\
& R_{\mathrm{e}}(\varphi)=\frac{a}{1+f+m-2 f \sin ^{2} \varphi},
\end{aligned}
$$

where $\varphi$ is the latitude, $h$ is the ellipsoidal height (in $\mathrm{km}$ ), and $H$ is the geopotential height (in $\mathrm{km}$ ); the constant $g_{0}$ is assigned to $9.80665 \mathrm{~m} \mathrm{~s}^{-2} ; g(\varphi)$ is the gravity on the geoid; $R_{\mathrm{e}}(\varphi)$ is the radius of curvature of the Earth at the latitude of $\varphi$; and the parameters $a=6378.137 \mathrm{~km}, f=$ $1 / 298.257223563, m=0.00344978650684$.

Since the humidity in layered, meteorological data are recorded as dew point temperature $\left(T_{\mathrm{d}}\right)$ or $\mathrm{RH}$ or specific humidity $(q)$ instead of partial pressure of water vapour $(e)$. The water vapour pressure needs to be computed first in the determination of $T_{\mathrm{m}}$ with $T_{\mathrm{d}}, \mathrm{RH}$, and $q$, i.e.

$$
\begin{aligned}
& e=f(P) \cdot 6.112 \exp \left(\frac{17.62 t}{243.12+t}\right) \\
& e=\frac{q P}{q+\varepsilon(1-q)}, \\
& \log _{10}(e)_{\operatorname{liquid}}=\log _{10}\left(\frac{\mathrm{RH}}{100}\right)+\log _{10}(f(P)) \\
& \quad+10.79574\left(1-\frac{273.16}{T}\right)-5.028 \log _{10}\left(\frac{T}{273.16}\right) \\
& \quad+1.50475 \times 10^{-4}\left(1-10^{-8.2969\left(\frac{T}{273.16}-1\right)}\right) \\
& \quad+0.42873 \times 10^{-3}\left(10^{-4.76955\left(1-\frac{273.16}{T}\right)}-1\right)
\end{aligned}
$$

$$
+0.78614
$$

$$
\begin{aligned}
& \log _{10}(e)_{\text {ice }}=\log _{10}\left(\frac{\mathrm{RH}}{100}\right)+\log _{10}(f(P)) \\
& -9.096853\left(\frac{273.16}{T}-1\right)-3.566506 \log _{10}\left(\frac{273.16}{T}\right) \\
& +0.876812\left(1-\frac{T}{273.16}\right)+0.78614,
\end{aligned}
$$

where $t$ is the temperature in Celsius degree, and $t=T-$ 273.15; $\varepsilon=M_{\mathrm{W}} / M_{\mathrm{d}}$ is the ratio of the molar masses of vapour and dry air, respectively; $f(P)$ is an enhancement factor defined as the ratio of the saturation vapour pressure of moist air to that of pure water vapour (WMO, 2000); Eqs. (A7) and (A8) are deduced from the Goff's formulation and the unit of water vapour pressure $e$ is $\mathrm{Pa}$ (Goff, 1957). $T_{\mathrm{m}}$ in this study is computed with $\mathrm{RH}$ data. Note that interpolations of meteorological measurements are not applied in Eq. (A1).

\section{Appendix B: Empirical $T_{m}$ models}

\section{B1 UNB3m}

Strictly, the UNB3m model is not a specific $T_{\mathrm{m}}$ model, but it can be used to calculate $T_{\mathrm{m}}$ from the following equation (Leandro et al., 2008):

$T_{\mathrm{m}}^{\mathrm{UNB} 3 \mathrm{~m}}=\left(T_{0}-\beta_{T} \cdot h\right)\left(1-\frac{\beta_{T} R}{g_{m}(\lambda+1)}\right)$,

where $T_{0}$ is the temperature at the mean sea level, $\lambda$ is the dimensionless water vapour pressure height factor, $\beta_{T}$ is temperature lapse rate, $g_{m}$ is the acceleration of gravity at the atmospheric column centroid, $R$ is the gas constant for dry air, and $h$ is the height of unknown position.

The UNB3m model neglects the longitudinal variations in $T_{\mathrm{m}}$. The meteorological variables in Eq. (B1), i.e. $T_{0}, \lambda$, and $\beta_{T}$, are linearly interpolated in latitudinal direction based on a simple look-up table.

\section{B2 GPT2w}

The GPT2w, an improved GPT model, was developed by Böhm et al. (2015). This empirical model can provide pressure, temperature, tropospheric delay, and $T_{\mathrm{m}}$ with the annual and semi-annual amplitudes. The updated model was established on a regular resolution of $5^{\circ}$ with monthly meteorological data of 10-year (2001-2010) ERA-Interim. The $T_{\mathrm{m}}$ is calculated by Eq. (B5), but the coefficients in this equation are determined based on a regular grid of 5 or $1^{\circ}$. Note that the GPT $2 \mathrm{w}$ is not specifically designed for $T_{\mathrm{m}}$ computation.

\section{B3 GWMT series models}

The GWMT series models are global models developed and consistently improved by Yao et al. using the state-of-the-art 
data sources and improved methodologies (Yao et al., 2015, 2014a, b, 2013, 2012).

The GWMT model was based on spherical harmonics of degree nine and order nine and is a function of the geodetic coordinates of the site, as expressed below:

$$
\begin{aligned}
& T_{\mathrm{m}}^{\mathrm{GWMT}}=\alpha_{1}+\alpha_{2} h+\alpha_{3} \cos \left(2 \pi \frac{\mathrm{DOY}-28}{365.25}\right), \\
& \alpha_{i}=\sum_{n=0}^{9} \sum_{m=0}^{n} P_{n m}(\sin \varphi) \cdot\left[A_{n m}^{i} \cos (m \lambda)\right. \\
& \left.\quad+B_{n m}^{i} \sin (m \lambda)\right] \quad(i=1 \text { or } 3)
\end{aligned}
$$

where the globally mean lapse rate of $T_{\mathrm{m}}$ and $\alpha_{2}$ is $-4.1 \mathrm{~K} \mathrm{~km}^{-1} ; \varphi, \lambda$, and $h$ are the latitude, longitude, and height of the site, respectively; DOY is the day of year; $P_{n m}$ is the Legendre function; $A_{n m}^{i}$ and $B_{n m}^{i}$ in Eq. (6) are two coefficients estimated from the least-squares estimation.

The GTm-II and GWMT models are developed using the same methodology but with different data.

Considering the semi-annual and diurnal variations in $T_{\mathrm{m}}$, the GTm-III model can be expressed as

$$
\begin{aligned}
& T_{\mathrm{m}}^{\mathrm{GTm}-\mathrm{III}}=\alpha_{1}+\alpha_{2} h+\alpha_{3} \cos \left(2 \pi \frac{\mathrm{DOY}-C_{1}}{365.25}\right) \\
& \quad+\alpha_{4} \cos \left(4 \pi \frac{\mathrm{DOY}-C_{2}}{365.25}\right)+\alpha_{5} \sin \left(2 \pi \frac{\mathrm{HOD}-C_{3}}{24}\right),
\end{aligned}
$$

where HOD is the hour of the day. The coefficients $\alpha_{i}(i=1$, $2, \ldots, 3)$ are expended to spherical harmonics similar with the case in GWMT and GTm-II.

Since the adjustment model in Eq. (B4) for the GTm-III is non-linear, the coefficients determined may be unstable or biased. Chen et al. (2014) established the GTm_N model with a global grid of $2.5^{\circ} \times 2.5^{\circ} \mathrm{NCEP}$ reanalysis data neglecting the diurnal variation in $T_{\mathrm{m}}$. The GTm_N model linearises the Eq. (B4) as (Chen et al., 2014):

$$
\begin{aligned}
& T_{\mathrm{m}}^{\mathrm{GTm} \_\mathrm{N}}=\alpha_{1}+\alpha_{2} h+\alpha_{3}^{\prime} \cos \left(2 \pi \frac{\mathrm{DOY}}{365.25}\right) \\
& +\beta_{3}^{\prime} \sin \left(2 \pi \frac{\mathrm{DOY}}{365.25}\right)+\alpha_{4}^{\prime} \cos \left(4 \pi \frac{\mathrm{DOY}}{365.25}\right) \\
& +\beta_{4}^{\prime} \sin \left(4 \pi \frac{\mathrm{DOY}}{365.25}\right) .
\end{aligned}
$$

All the aforementioned models are based on such an assumption that the vertical lapse rate of $T_{\mathrm{m}}$ is the same over the globe, i.e. the $\alpha_{2}$ in these equations are constants. In fact, this assumption is not always true (He et al., 2013). Therefore, the horizontal variation of $T_{\mathrm{m}}$ lapse rate $(\beta)$ is considered in the GWMT-IV model. It is a function of the horizontal location. Thus, the global $T_{\mathrm{m}}$ at the height of $h$ can be expressed as a function of the mean sea level $T_{\mathrm{m}}\left(T_{\mathrm{m}}^{0}\right)$ and $\beta$ in Eq. (9), both of which can be further separated into annual and semiannual components. Parameters of both amplitude and initial phase for annual and semi-annual variations are similarly expended into a spherical harmonics form.

$T_{\mathrm{m}}^{\mathrm{GWMT}-\mathrm{IV}}=T_{\mathrm{m}}^{0}+\beta \cdot h$

\section{Appendix C: Approximated propagation of RMSE}

Given a series of observations $V$ collected at the same time (Ning et al., 2016):

$V_{i}=\widetilde{V}+M+\varepsilon_{i}$,

where $M$ is a time-independent bias (systematic error); $\widetilde{V}$ is the true value of observations, $V_{i}$; and $\varepsilon_{i}$ is the zero-mean stationary Gaussian random error. Hence, the RMSE of the difference between estimates and true values is given by

$\operatorname{RMSE}_{V}=\sqrt{\frac{1}{N} \sum_{i=1}^{N}\left(V_{i}-\widetilde{V}\right)^{2}}=\sqrt{\frac{1}{N} \sum_{i=1}^{N}\left(M+\varepsilon_{i}\right)^{2}}$,

where $N$ is the total number of observations. Since the mean value of $\varepsilon_{i}$ will be close to zero for massive repeated observations, Eq. (C2) can be approximately reduced to

$\operatorname{RMSE}_{V}=\sqrt{\frac{1}{N} \sum_{i=1}^{N}\left(M^{2}+\varepsilon_{i}^{2}\right)}=\sqrt{M^{2}+\sigma_{\varepsilon}^{2}}$,

where $\sigma_{\varepsilon}$ is the standard deviation of $\varepsilon$. As can be seen from this equation, the RMSE will be identical to standard deviation when observations are free of systematic bias. Consider a linear or non-linear function $W=f(V): R \longrightarrow R$ whose RMSE can be expressed by

$\operatorname{RMSE}_{W}=\sqrt{\frac{1}{N} \sum_{i=1}^{N}\left[f\left(V_{i}\right)-f(\widetilde{V})\right]^{2}}$.

Using first-order Taylor expansion, we have

$f(V)-\left.f(\widetilde{V}) \approx(V-\widetilde{V}) \cdot \frac{\partial f(V)}{\partial V}\right|_{V=\widetilde{V}}$.

Substituting Eq. (C5) into Eq. (C4),

$$
\begin{aligned}
\operatorname{RMSE}_{W} & \left.\approx \frac{\partial f(V)}{\partial V}\right|_{V=\widetilde{V}} \cdot \sqrt{\frac{1}{N} \sum_{i=1}^{N}\left(V_{i}-\tilde{V}\right)^{2}} \\
& =\left.\frac{\partial f(V)}{\partial V}\right|_{V=\tilde{V}} \cdot \operatorname{RMSE}_{V} .
\end{aligned}
$$

As a result, the RMSE of $f(V)$ can be approximately propagated from that of $V$. 


\section{The Supplement related to this article is available online at https://doi.org/10.5194/amt-10-2045-2017-supplement.}

Competing interests. The authors declare that they have no conflict of interest.

Acknowledgements. We would like to thank the NOAA/OAR/ESRL PSD (Boulder, Colorado, USA) for providing NCEP-DOE Reanalysis 2 data (2010-2014), the Department of Atmospheric Science in the University of Wyoming for providing access to radiosonde data in 2014, the GGOS (Global Geodetic Observing System) Atmosphere for providing 2014 surface $T_{\mathrm{m}}$ product. Jennifer Anderson and Timothy Kodikara at RMIT University and the three anonymous reviewers are thanked for their assistance in evaluating this paper. This research is partially supported by the Australian Research Council grant (ARCLP130100243) and the National Science Foundation of China (No. 41404033).

Edited by: J. Jones

Reviewed by: three anonymous referees

\section{References}

Askne, J. and Nordius, H.: Estimation of Tropospheric Delay for Microwaves from Surface Weather Data, Radio Sci., 22, 379386, https://doi.org/10.1029/RS022i003p00379, 1987.

Bevis, M., Businger, S., Herring, T. A., Rocken, C., Anthes, R. A., and Ware, R. H.: Gps Meteorology - Remote-Sensing of Atmospheric Water-Vapor Using the Global Positioning System, J. Geophys. Res.-Atmos., 97, 15787-15801, 1992.

Bevis, M., Businger, S., Chiswell, S., Herring, T. A., Anthes, R. A., Rocken, C., and Ware, R. H.: Gps Meteorology - Mapping Zenith Wet Delays onto Precipitable Water, J. Appl. Meteorol., 33, 379-386, https://doi.org/10.1175/15200450(1994)033<0379:Gmmzwd>2.0.Co;2, 1994.

Böhm, J., Heinkelmann, R., and Schuh, H.: Short note: a global model of pressure and temperature for geodetic applications, J. Geodesy, 81, 679-683, https://doi.org/10.1007/s00190-0070135-3, 2007.

Böhm, J., Moller, G., Schindelegger, M., Pain, G., and Weber, R.: Development of an improved empirical model for slant delays in the troposphere (GPT2w), GPS Solut., 19, 433-441, https://doi.org/10.1007/s10291-014-0403-7, 2015.

Buizza, R., Houtekamer, P. L., Toth, Z., Pellerin, G., Wei, M. Z., and Zhu, Y. J.: A comparison of the ECMWF, MSC, and NCEP global ensemble prediction systems, Mon. Weather Rev., 133, 1076-1097, https://doi.org/10.1175/Mwr2905.1, 2005.

Champollion, C., Masson, F., Van Baelen, J., Walpersdorf, A., Chéry, J., and Doerflinger, E.: GPS monitoring of the tropospheric water vapor distribution and variation during the 9 September 2002 torrential precipitation episode in the Cévennes (southern France), J. Geophys. Res.-Atmos., 109, D24102, https://doi.org/10.1029/2004JD004897, 2004.
Chen, P. and Yao, W.: GTm_X: A New Version Global Weighted Mean Temperature Model, China Satellite Navigation Conference (CSNC) 2015 Proceedings: Volume II, 605-611, 2015.

Chen, P., Yao, W. Q., and Zhu, X. J.: Realization of global empirical model for mapping zenith wet delays onto precipitable water using NCEP re-analysis data, Geophys. J. Int., 198, 1748-1757, https://doi.org/10.1093/gji/ggu223, 2014.

Choy, S., Zhang, K., Wang, C.-S., Li, Y., and Kuleshov, Y.: Remote Sensing of the Earth's Lower Atmosphere during Severe Weather Events using GPS Technology: a Study in Victoria, Australia, Proceedings of the 24th International Technical Meeting of The Satellite Division of the Institute of Navigation (ION GNSS 2011), 559-571, 2001.

Davis, J. L., Herring, T. A., Shapiro, I. I., Rogers, A. E. E., and Elgered, G.: Geodesy by Radio Interferometry - Effects of Atmospheric Modeling Errors on Estimates of Baseline Length, Radio Sci., 20, 1593-1607, https://doi.org/10.1029/RS020i006p01593, 1985.

Duan, J. P., Bevis, M., Fang, P., Bock, Y., Chiswell, S., Businger, S., Rocken, C., Solheim, F., vanHove, T., Ware, R., McClusky, S., Herring, T. A., and King, R. W.: GPS meteorology: Direct estimation of the absolute value of precipitable water, J. Appl. Meteorol., 35, 830-838, https://doi.org/10.1175/15200450(1996)035<0830:Gmdeot>2.0.Co;2, 1996.

Emardson, T. R. and Derks, H. J. P.: On the relation between the wet delay and the integrated precipitable water vapour in the European atmosphere, Meteorol. Appl., 7, 61-68, https://doi.org/10.1017/S1350482700001377, 2000.

Fornberg, B. and Zuev, J.: The Runge phenomenon and spatially variable shape parameters in RBF interpolation, Comput. Math. Appl., 54, 379-398, https://doi.org/10.1016/j.camwa.2007.01.028, 2007.

Ge, S.: GPS radio occultation and the role of atmospheric pressure on spaceborne gravity estimation over Antarctica, The Ohio State University, 2006.

Goff, J. A.: Saturation pressure of water on the new Kelvin temperature scale, Transactions of the American Society of Heating and Ventilating Engineers, 63, 347-353, 1957

Gutman, S. I. and Benjamin, S. G.: The role of ground-based GPS meteorological observations in numerical weather prediction, GPS Solut., 4, 16-24, 2001.

He, C., Yao, Y., Zhao, D., Li, K., and Qian, C.: GWMT Global Atmospheric Weighted Mean Temperature Models: Development and Refinement, China Satellite Navigation Conference (CSNC) 2013 Proceedings, 487-500, 2013.

Jade, S., Vijayan, M. S. M., Gaur, V. K., Prabhu, T. P., and Sahu, S. C.: Estimates of precipitable water vapour from GPS data over the Indian subcontinent, J. Atmos. Sol.-Terr. Phy., 67, 623-635, https://doi.org/10.1016/j.jastp.2004.12.010, 2005.

Jin, S. and Luo, O.: Variability and climatology of PWV from global 13-year GPS observations, IEEE T. Geosci. Remote Sens., 47, 1918-1924, 2009.

Kanamitsu, M., Ebisuzaki, W., Woollen, J., Yang, S. K., Hnilo, J. J., Fiorino, M., and Potter, G. L.: NCEP-DOE AMIPII reanalysis (R-2), B. Am. Meteorol. Soc., 83, 1631-1643, https://doi.org/10.1175/Bams-83-11-1631, 2002.

Kwon, H. T., Jung, E. H., and Lim, G. H.: A comparison of GPS- and NWP-derived PW data over the Korean 
Peninsula, Advances in Atmospheric Sciences, 27, 871-882, https://doi.org/10.1007/s00376-009-9069-4, 2010.

Leandro, R. F., Langley, R. B., and Santos, M. C.: UNB3m_pack: a neutral atmosphere delay package for radiometric space techniques, GPS Solut., 12, 65-70, https://doi.org/10.1007/s10291007-0077-5, 2008.

Li, Z. H., Muller, J. P., and Cross, P.: Comparison of precipitable water vapor derived from radiosonde, GPS, and ModerateResolution Imaging Spectroradiometer measurements, J. Geophys. Res.-Atmos., 108, https://doi.org/10.1029/2003jd003372, 2003.

Liu, J.: Tropopause heights with its applications in the key parameters of the troposphere models Master, School of Geodesy and Geomatics, Wuhan University, Wuhan, 2015.

Mendes, V., Prates, G., Santos, L., and Langley, R.: An evaluation of the accuracy of models for the determination of the weighted mean temperature of the atmosphere, Proceedings of ION, 433438, 2000.

Ning, T., Wang, J., Elgered, G., Dick, G., Wickert, J., Bradke, M., Sommer, M., Querel, R., and Smale, D.: The uncertainty of the atmospheric integrated water vapour estimated from GNSS observations, Atmos. Meas. Tech., 9, 79-92, https://doi.org/10.5194/amt-9-79-2016, 2016.

Picard, A., Davis, R. S., Glaser, M., and Fujii, K.: Revised formula for the density of moist air (CIPM-2007), Metrologia, 45, 149155, https://doi.org/10.1088/0026-1394/45/2/004, 2008.

Prasad, A. K. and Singh, R. P.: Validation of MODIS Terra, AIRS, NCEP/DOE AMIP-II Reanalysis-2, and AERONET Sun photometer derived integrated precipitable water vapor using ground-based GPS receivers over India, J. Geophys. Res.Atmos., 114, D05107, https://doi.org/10.1029/2008jd011230, 2009.

Ross, R. J. and Rosenfeld, S.: Estimating mean weighted temperature of the atmosphere for Global Positioning System applications, J. Geophys. Res.-Atmos., 102, 21719-21730, https://doi.org/10.1029/97jd01808, 1997.

Ross, R. J. and Rosenfeld, S.: Correction to "Estimating mean weighted temperature of the atmosphere for Global Positioning System applications" by Rebecca J. Ross and Simon Rosenfeld, J. Geophys. Res.-Atmos., 104, 27625-27625, 1999.

Saastamoinen, J.: Contributions to the theory of atmospheric refraction, B. Geod., 105, 279-298, 1972.

Schueler, T., Pósfay, A., Hein, G. W., and Biberger, R.: A global analysis of the mean atmospheric temperature for GPS water vapor estimation, Proceedings of ION-GPS, 11-14, 2001.

Song, S., Zhu, W., Ding, J., and Cheng, Z.: Coming process of Meiyu season in 2002 over Yangtz river delta monitored by Shanghai GPS network, Progress in Astronomy, 21, 180-184, 2003.

Song, S. L., Zhu, W. Y., Ding, J. C., Liao, X. H., Cheng, Z. Y., and Ye, Q. X.: Near Real-Time Sensing of PWV from SGCAN and the Application Test in Numerical Weather Forecast, Chinese J. Geophys.-Ch., 47, 719-727, 2004.

Van Baelen, J. and Penide, G.: Study of water vapor vertical variability and possible cloud formation with a small network of GPS stations, Geophys. Res. Lett., 36, L02804, https://doi.org/10.1029/2008GL036148, 2009.
Wang, J., Zhang, L., and Dai, A.: Global estimates of watervapor-weighted mean temperature of the atmosphere for GPS applications, J. Geophys. Res.-Atmos., 110, D21101, https://doi.org/10.1029/2005JD006215, 2005.

Wang, J., Zhang, L., Dai, A., Van Hove, T., and Van Baelen, J.: A near-global, 2-hourly data set of atmospheric precipitable water from ground-based GPS measurements, J. Geophys. Res.Atmos., 112, D11107, https://doi.org/10.1029/2006JD007529, 2007.

Wang, X., Dai, Z., Cao, Y., and Song, L.: Weighted mean temperature $\mathrm{T}(\mathrm{m})$ statistical analysis in ground-based GPS in China, Geomatics and Information Science of Wuhan University, 36, 412-416, 2011.

Wang, X. M., Zhang, K. F., Wu, S. Q., Fan, S. J., and Cheng, Y. Y.: Water vapor-weighted mean temperature and its impact on the determination of precipitable water vapor and its linear trend, J. Geophys. Res.-Atmos., 121, 833-852, https://doi.org/10.1002/2015jd024181, 2016.

WMO: General Meteorological Standards and Recommended Practices, Appendix A, WMO Technical Regulations, edited by: WMO, Geneva, Switzerland, 2000.

Yang, X. H., Sass, B. H., Elgered, G., Johansson, J. M., and Emardson, T. R.: A comparison of precipitable water vapor estimates by an NWP simulation and GPS observations, J. Appl. Meteorol., 38, 941-956, https://doi.org/10.1175/15200450(1999)038<0941:Acopwv>2.0.Co;2, 1999.

Yao, Y. B., Zhu, S., and Yue, S. Q.: A globally applicable, season-specific model for estimating the weighted mean temperature of the atmosphere, J. Geodesy, 86, 1125-1135, https://doi.org/10.1007/s00190-012-0568-1, 2012.

Yao, Y. B., Zhang, B., Yue, S. Q., Xu, C. Q., and Peng, W. F.: Global empirical model for mapping zenith wet delays onto precipitable water, J. Geodesy, 87, 439-448, https://doi.org/10.1007/s00190013-0617-4, 2013.

Yao, Y. B., Xu, C. Q., Zhang, B., and Cao, N.: GTm-III: a new global empirical model for mapping zenith wet delays onto precipitable water vapour, Geophys. J. Int., 197, 202-212, https://doi.org/10.1093/gji/ggu008, 2014a.

Yao, Y. B., Zhang, B., Xu, C. Q., and Yan, F.: Improved one/multi-parameter models that consider seasonal and geographic variations for estimating weighted mean temperature in ground-based GPS meteorology, J. Geodesy, 88, 273-282, https://doi.org/10.1007/s00190-013-0684-6, 2014b.

Yao, Y. B., Xu, C. Q., Zhang, B., and Cao, N.: A global empirical model for mapping zenith wet delays onto precipitable water vapor using GGOS Atmosphere data, Sci. China Earth Sci., 58, 1361-1369, https://doi.org/10.1007/s11430-014-5025-y, 2015.

Zhang, K. F., Manning, T., Wu, S. Q., Rohm, W., Silcock, D., and Choy, S.: Capturing the Signature of Severe Weather Events in Australia Using GPS Measurements, IEEE J-Stars, 8, 18391847, https://doi.org/10.1109/Jstars.2015.2406313, 2015.

Zhang, M., Ni, Y. Q., and Zhang, F. Q.: Variational assimilation of GPS precipitable water vapor and hourly rainfall observations for a meso-beta scale heavy precipitation event during the 2002 Mei-Yu season, Adv. Atmos. Sci., 24, 509-526, https://doi.org/10.1007/s00376-007-0509-8, 2007. 